Portland State University

PDXScholar

Spring 6-21-2013

\title{
Understanding Travel Modes to Non-work \\ Destinations: Analysis of an Establishment Survey in Portland, Oregon
}

Christopher D. Muhs

Portland State University

Follow this and additional works at: https://pdxscholar.library.pdx.edu/open_access_etds

Part of the Civil Engineering Commons, and the Urban Studies and Planning Commons Let us know how access to this document benefits you.

Recommended Citation

Muhs, Christopher D., "Understanding Travel Modes to Non-work Destinations: Analysis of an Establishment Survey in Portland, Oregon" (2013). Dissertations and Theses. Paper 1094.

https://doi.org/10.15760/etd.1094

This Thesis is brought to you for free and open access. It has been accepted for inclusion in Dissertations and Theses by an authorized administrator of PDXScholar. Please contact us if we can make this document more accessible: pdxscholar@pdx.edu. 
Understanding Travel Modes to Non-work Destinations: Analysis of an Establishment

Survey in Portland, Oregon

by

Christopher Devlin Muhs

A thesis submitted in partial fulfillment of the requirements for the degree of

\author{
Master of Science \\ in \\ Civil and Environmental Engineering
}

\begin{abstract}
Thesis Committee:
Kelly Clifton, Chair

Christopher Monsere

Jennifer Dill
\end{abstract}

Portland State University

2013 
(C) 2013 Christopher Devlin Muhs 


\begin{abstract}
During the past three decades, research in travel behavior has generally proceeded from broad-level, aggregate analysis of mode share-the proportions of walking, bicycling, transit, and vehicle travel occurring in traffic analysis zones, census tracts, neighborhood, or other geographical units - to fine-grained, disaggregate analysis of mode choices and other trip-making attributes at the individual level. One potential issue is whether there are differences in the types of conclusions drawn from results of analyses performed at these different levels, as these results directly inform transportation planning and policy.
\end{abstract}

This thesis aims in part to confirm whether the types of conclusions drawn from different levels of analysis are different, and to what extent. We also examine the relationships between the built environment and non-work travel choices from a unique analysis perspective. To do this, we use data from a 2011 travel intercept survey in the Portland, Oregon metropolitan region that was administered at convenience store, bar, and restaurant establishments. We estimate, for each of the travel modes — walk, bicycle, and automobile - two analysis models: one binary logistic regression model for mode choice of the individual traveler going to the establishment and one multiple linear regression model for mode share of shoppers at the establishment. Both models control for socio-demographics, trip characteristics, and built environment measures of travelers. For the binary logistic regression models, the data are disaggregate and particular to the individual traveler. These models also controlled for attitudes and preference towards 
travel modes. For the multiple regression models, data are aggregated to the establishment. The built environment data in each model represent characteristics of urban form surrounding the establishment. The data being oriented to the destination-end of the trip, as well as providing controls on land use make this analysis unique in the literature, as most non-work travel studies use residential-based data.

Results suggest that analyses performed at the two different levels provide policyrelevant but somewhat different conclusions. In general, characteristics of the individual and the trip have stronger associations with mode choices of individuals than when aggregated to the establishment and analyzed against the mode share patterns of shoppers. Instead, mode shares have stronger relationships with characteristics of the built environment. The built environment surrounding the destination has a much more pronounced association with mode shares at the establishment than with mode choices of individuals. The results highlight the usefulness of simple aggregate analysis, when appropriate. We also find large differences between modes in which characteristics are important for mode choice and mode share. Walking and automobile models behave somewhat similarly but in opposite directions, while bicycling behaves quite differently. These differences suggest on their own a move away from non-motorized travel to be considered as equivalent or assessed as one item in research and in practice. 


\section{Acknowledgements}

Thank you Dr. Kelly Clifton for motivation, encouragement, and support before, during, and after the many iterations of this thesis. Thank you Dr. Chris Monsere and Dr. Jennifer Dill for your reviews and assistance as committee members. Thanks to the students who helped review and edit this thesis. Thank you family, friends old and new, and colleagues for support throughout my adventures. Additionally, I gratefully acknowledge the Oregon Transportation, Research and Education Consortium (OTREC), or is it the National Institute for Transportation and Communities (NITC), for funding the project from which this research originates. 


\section{Table of Contents}

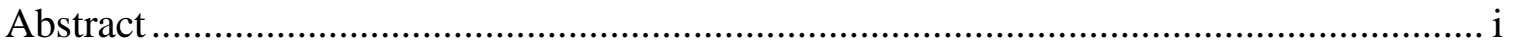

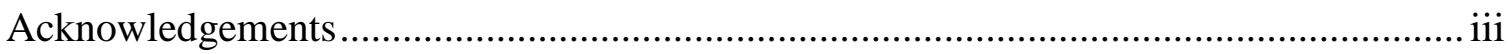

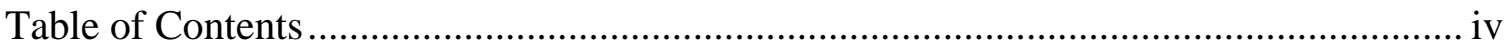

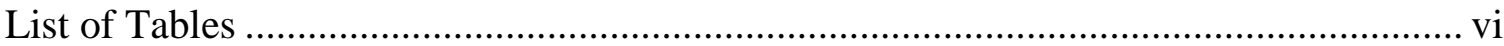

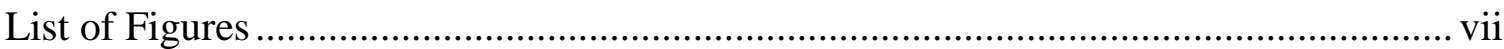

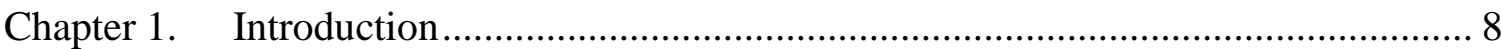

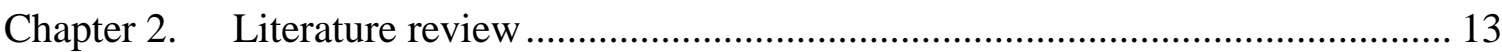

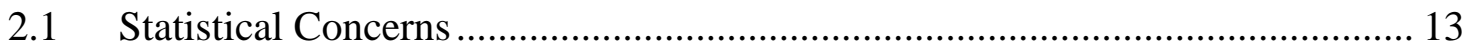

2.2 Non-work travel and the built environment ................................................ 15

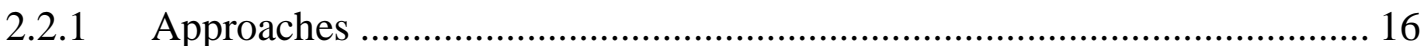

2.2.2 Findings on Mode Choice ................................................................ 18

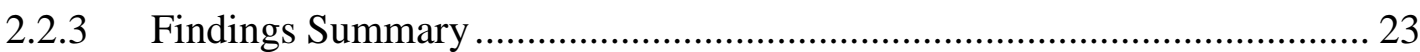

2.3 Approach and Contribution................................................................ 24

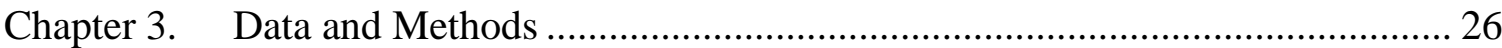

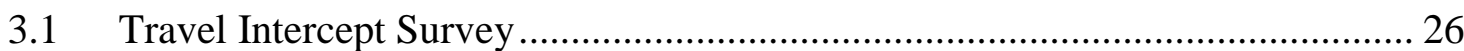

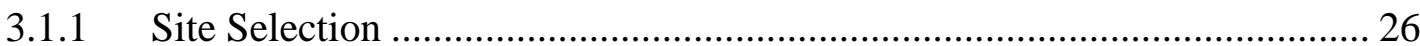

3.1.2 Survey Method \& Instrument ............................................................ 29

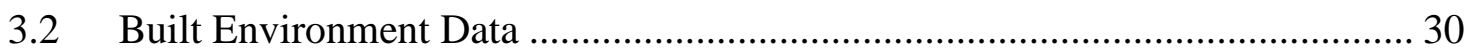

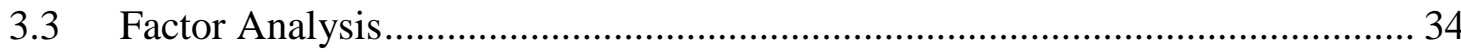

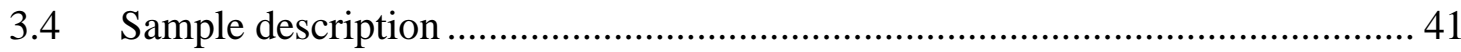

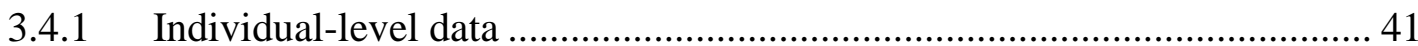

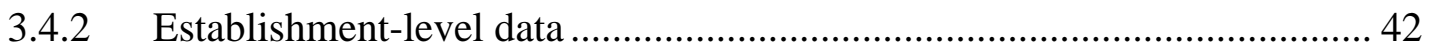

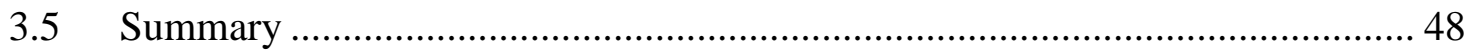

Chapter 4. Analysis Methods \& Results............................................................... 49

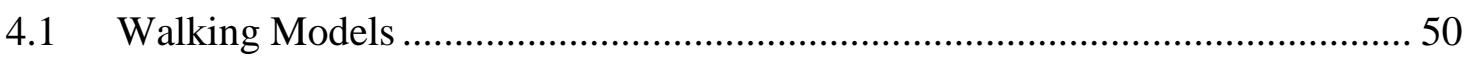

4.1.1 Binary Logit Model - Choice to Walk ................................................... 50

4.1.2 Linear Regression - Walk Mode Share ................................................. 52

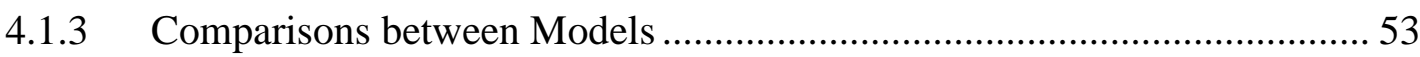

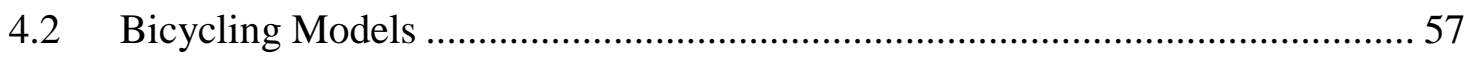

4.2.1 Binary Logit Model - Choice to Ride Bicycle ....................................... 57

4.2.2 Linear Regression - Bike Mode Share .................................................. 59 


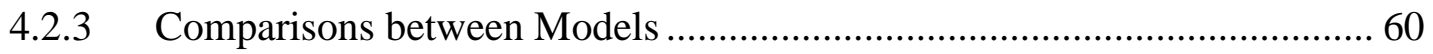

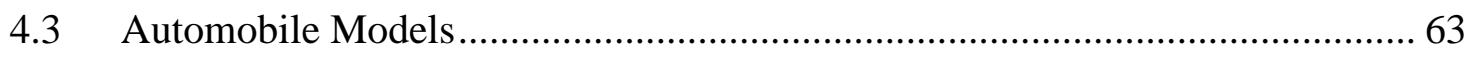

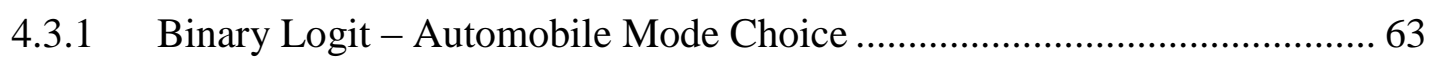

4.3.2 Linear Regression - Automobile Mode Share......................................... 65

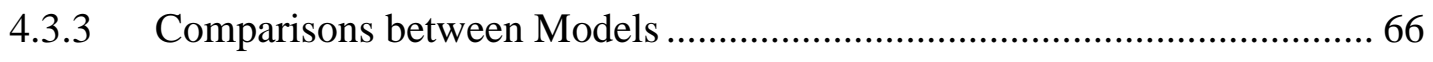

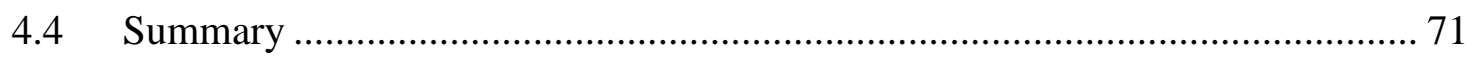

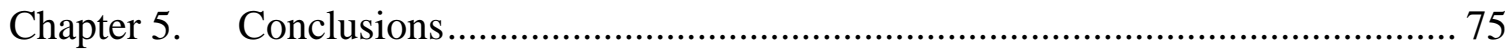

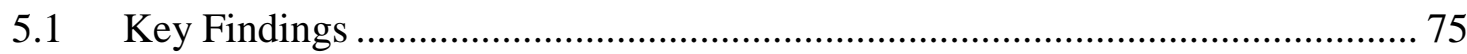

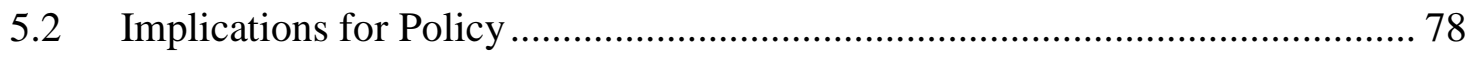

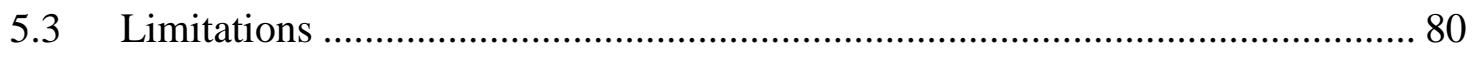

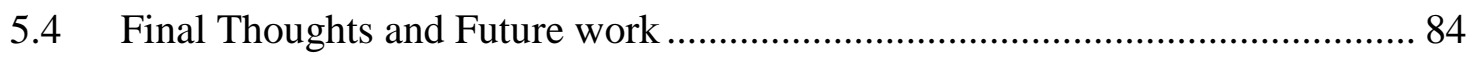

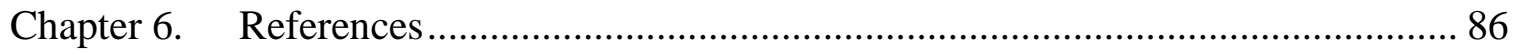

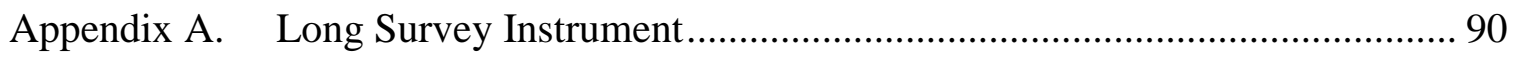

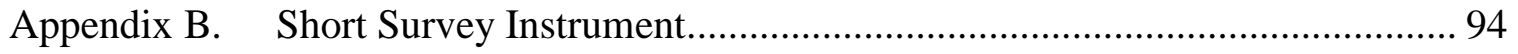

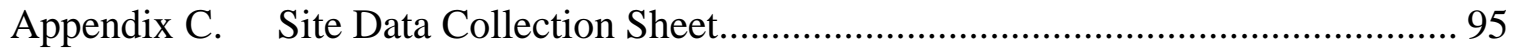

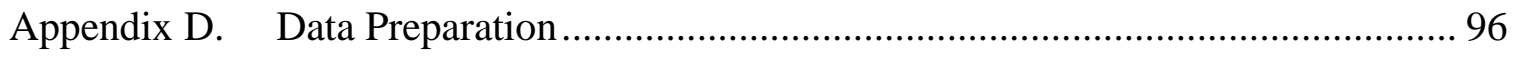

Appendix E. Standardized Estimates for Binary Logistic Regression Models ............ 98 


\section{List of Tables}

Table 3-1. Convenience Store, Restaurant, and Bar Survey Sample Size ...................... 30

Table 3-2. Built Environment Measures and Sources ................................................... 31

Table 3-3. Average Site Characteristics of Establishments ........................................ 33

Table 3-4. Correlations between Built Environment Measures ...................................... 34

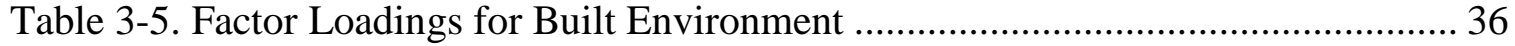

Table 3-6. Individual Characteristics from Long Survey Sample ................................. 46

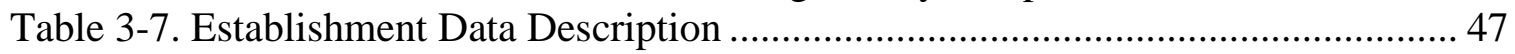

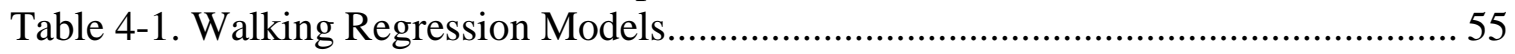

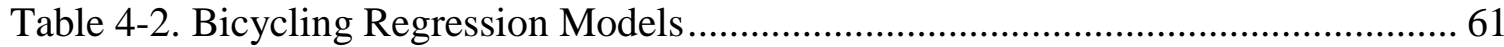

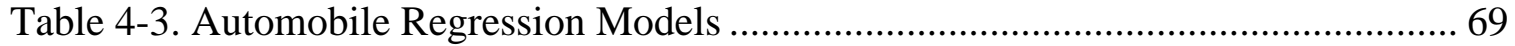




\section{List of Figures}

Figure 1-1. Conceptual Diagram of Mode Choices and Mode Shares .......................... 11

Figure 3-1. Locations of Survey Establishments ...................................................... 28

Figure 3-2. Scree Plot for Built Environment Factor Analysis ..................................... 37

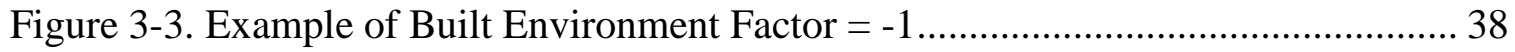

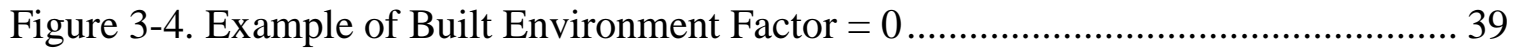

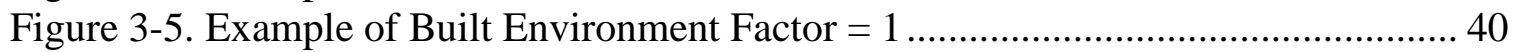

Figure 3-6. Observed Mode Share ......................................................................... 43

Figure 3-7. Mode Share Map of Survey Establishments ............................................ 44

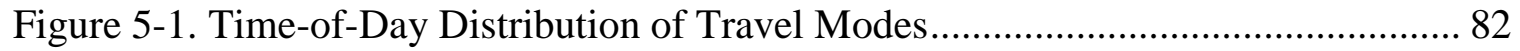




\section{Chapter 1. Introduction}

As computing capacity has increased and transport and land use data availability has responded accordingly, research in travel behavior has largely moved away from aggregate level analysis-for example transportation analysis zones (TAZs) and neighborhoods. Instead, the focus has shifted to more behaviorally explicit, disaggregate policy inquiries that aim to understand individual level attributes and their relation to travel choices. These approaches can inform behavioral change, given built environment contexts.

But, land use and transportation planning is still largely rooted in place-based perspectives that aim to influence the attributes of locations in order to increase travel efficiencies or promote use of non-automobile modes. To achieve policy goals of increasing active transportation and reduced automobile travel in urban areas, a combination of both place-based and individual-oriented approaches are appropriate (Taylor \& Ampt, 2003). However, these separate levels of policy may require differing research and analysis perspectives to understand implications and inform implementation.

The purpose of this thesis is to contribute to the land use and travel behavior literature by examining the influences of individual traveler and establishment built environment characteristics on travel mode choice through both aggregate and disaggregate analysis. Logically, aggregate-level analysis, such as analyzing mode shares at sites or neighborhoods, may be best-suited to inform place-based policies, and disaggregate-level analysis of individual behavior best-suited for behavioral modification, education, or other personally-oriented programs. This is not to say that disaggregate analysis cannot 
inform place-based policy. But in the other direction, drawing conclusions about individuals from aggregate-level analysis is subject to statistical issues like the ecological inference fallacy (Robinson, 2009).

Existing research reveals important connections between travel behavior and the built environment (Ewing \& Cervero, 2001; Frank \& Engelke, 2001; Saelens \& Handy, 2008; Saelens, Sallis, \& Frank, 2003). At the site, establishment, or zonal level, we know that macro-level characteristics of the environment like population density, employment density, land use mixing, and street network density are related to vehicle trips and miles of vehicle travel (Ewing \& Cervero, 2001). At the individual person level, factors like travel times, distances, socio-demographics, attitudes and perceptions, and built environment attributes affect choice of mode (Frank \& Engelke, 2001; Kitamura, Mokhtarian, \& Laidet, 1997; Saelens et al., 2003). Existing research has assessed behavior at both levels, with most recent studies focusing on disaggregate travel by individuals or households. Because the analysis specifications and travel attributes of interest vary widely across studies, the strength of the relationships in the results also varies widely (Cao, Mokhtarian, \& Handy, 2009; Ewing \& Cervero, 2001). In many cases, the relationships between travel and the built environment are not as strong as attributed to socio-demographic characteristics (Ewing \& Cervero, 2001). More recent studies have included attitudes, but they are fewer in number (Ewing \& Cervero, 2010).

The objective of this study is to examine the socio-demographic and built environment relationships with mode choice for individual visitors to establishments for non-work 
travel and compare these results to establishment level analysis of mode shares. Specifically, the questions we seek to answer are the following:

1. What are the relationships between the built environment and mode choices?

2. How do these relationships differ between travel modes?

3. Do built environment attributes have a more pronounced association with mode shares at the establishment level than mode choices at the individual level?

4. How do socio-demographic characteristics and attitudes impact personal travel choices?

5. What are the key differences in comparing results at the different analysis levels?

To do this, we use a customer intercept survey at various establishments-convenience stores, restaurants, and bars. The analysis relies on destination-based data, unlike a majority of the travel behavior research which tends to rely on data collected from home locations. Also, few other studies control for specific land use types.

Figure 1-1 shows a conceptual diagram framing the research in this study. In our example, mode shares at establishments are a function of aggregated individual characteristics - average socio-demographics and psychological factors of the customer base computed from individual-level data - and place characteristics describing the built environment around the study establishments. Disaggregate travel mode choices of individuals traveling to establishments are a function of individual psychological factors and socio-demographic attributes, as well as the same built environment characteristics surrounding the establishment. 


\section{Aggregate Level}

\section{Individual Characteristics}

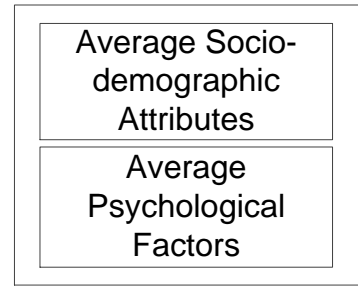

\section{Place Characteristics}

Built Environment Attributes around Establishment

\section{Disaggregate Level}

\section{Individual Characteristics}

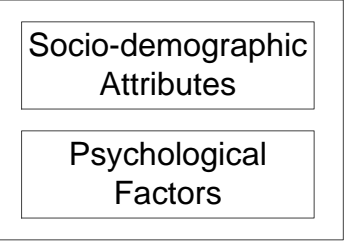

Place Characteristics

Built Environment Attributes around Establishment

\section{Figure 1-1. Conceptual Diagram of Mode Choices and Mode Shares}

By exploring the questions above and performing individual-level analysis and aggregate establishment-level analysis derived from the same dataset, this research will reveal how the different levels work in concert while exploring destination-based analysis of nonwork travel data. The information should lend insight into what the "appropriate" level of analysis may be, and we will address statistical concerns that occur with aggregation.

This thesis is structured in this general outline. Chapter 2 reviews related literature from the non-work travel, mode choice, and statistical areas to identify the contribution of this study. Chapter 3 describes the data from a 2011 establishment intercept survey in Portland, Oregon and the multiple regression and logistic regression methods used in analysis. Chapter 4 presents the analysis models and results. Findings showed that several key differences exist between disaggregate and aggregate analysis and across travel 
modes. In general, characteristics of the individual and the trip had stronger associations with mode choice of individuals than when aggregated to the establishment and analyzed against the mode share patterns of shoppers. Instead, mode shares had stronger relationships with characteristics of the built environment. Findings also showed that the bicycle mode behaves empirically differently than walking and automobile modes. Walk and automobile models tended to have similar but opposite results, while bicycle models were quite different. Chapter 5 summarizes the main takeaways and their implications for policy. The paper concludes with recommendations for future work, including a multilevel analysis approach. 


\section{Chapter 2. Literature review}

Over the past three decades, a very large body of research has emerged on how built environments influence travel. Studies have examined travel in many dimensions: the amount of trips, the frequency of trips, trip destinations and trip lengths, and travel modes. Measures of the built environment are included as continuous objective measures, subjective measures derived from survey participants, or categorical measures derived by researchers.

Travel is usually analyzed at either an aggregate level or a disaggregate level. Aggregate analyses are typically performed to assess mode splits or vehicle miles traveled (VMT) at the level of TAZs, census tracts, or metropolitan areas. Disaggregate analyses are typically executed at the level of the individual or household, and outcomes are often individual travel mode choices or number of trips made by mode. Disaggregate analysis allows for more complex models, as there is finer detail in spatial, temporal, and personal information (Handy, Boarnet, Ewing, \& Killingsworth, 2002).

This review begins with addressing statistical concerns, then outlines approaches to analyze non-work travel mode choice, then highlights findings from the non-work travel and built environment literature. We then explain our research approach and contribution.

\subsection{Statistical Concerns}

Rajamani et al. (2003) outlined four possible combinations of geographic scale and level of analysis for transportation and land use behavioral studies:

1. Aggregate spatial data and aggregate socio-demographics

2. Aggregate spatial data and disaggregate socio-demographics 
3. Disaggregate spatial data and aggregate socio-demographics

4. Disaggregate spatial data and disaggregate socio-demographics

Few (if any) studies have used the third framework, as it is inherently subject to the ecological inference problem (Robinson, 2009). King (1997, p. xv) describes the ecological inference problem as drawing inaccurate conclusions about individuals through "using aggregate (i.e. 'ecological') data to infer discrete individual-level relationships of interest when individual-level data are not available." This problem is avoided in the first, second, and fourth frameworks above. To our knowledge, no studies have compared the conclusions drawn about travel from these different analysis frameworks, which we do in this thesis.

Earlier (pre-1990s and 2000s) studies were generally more aggregate (framework one) for several reasons. First, before the 1990s, household travel surveys were mainly concerned with automobile, then transit travel at a regional scale (Clifton \& Muhs, 2012). Interest in walking and bicycling trips has surged since then, necessitating finer scale geographies for analysis, as aggregate census tract and TAZ geographies are sometimes too large to plausibly analyze walking and bicycling trips (Schneider, 2011). Second, availability of detailed spatial data was low before the 1990s and geographic information systems software allowing fast disaggregate spatial data analysis was not prolific. Third, the state of the art in the late 1980s and early 1990s was agent-based simulation for activity-based travel models (Pas, 1985), which also drove the direction of analysis towards the disaggregate level. 


\subsection{Non-work travel and the built environment}

Many studies have analyzed commuting trips and found their characteristics to be different than non-work trips. ${ }^{1}$ This review focuses on the latter. Non-work travel accounts for $81 \%$ of trips and $75 \%$ of person miles traveled in the United States (Santos, McGucklin, Nakamoto, Gray, \& Liss, 2011, p. 13). In addition, non-work trips are generally more flexible and discretionary than work trips and thus may be influenced by urban form to a greater degree than are work trips (Handy, 1996; Rajamani et al., 2003).

Aggregate mode share studies are not abundant in the non-work travel literature. Some studies (Bochner, Hooper, Sperry, \& Dunphy, 2011; Clifton, Currans, \& Muhs, 2012; Handy, Shafizadeh, \& Schneider, 2013) have examined trip rates at the site level to assess or develop alternatives to Institute of Transportation Engineers' Trip Generation rates (Institute of Transportation Engineers, 2012), but the focus of this work has been to analyze person trip rates by mode, rather than a direct focus of analysis on mode shares. Other studies have utilized employee surveys to examine travel behavior at the workplace (Dill \& Wardell, 2007; Naess \& Sandberg, 1996). These efforts have sought to determine ways to increase commuting by transit, walking, and biking, but do not concern non-work travel. Other existing studies of mode share have mainly been performed using census commuting data (for example: Cervero \& Gorham, 1995; Ewing, Pendall, \& Chen, 2003; Messenger \& Ewing, 1996) that is available at census blocks, census tracts, and larger geographies. For these and reasons described in section 2.1, most studies in this review

\footnotetext{
1 "Non-work" travel includes travel to reach shops, services, restaurants, entertainment, and other commercial activities, as well as travel for social interactions and travel for recreation.
} 
concern individual-level disaggregate non-work travel. Here we focus on approaches to analyze non-work travel choice and then highlight findings of individual studies.

\subsubsection{Approaches}

To study the relationships between travel choices and the environment, researchers often estimate logistic regression models that predict the probability of choosing a single outcome, a particular travel mode (Handy et al., 2002). The model structures can be such that the outcome variable is a binary choice, with one outcome against all other outcomes, or can be one choice within a specified choice set. Multinomial and nested logit models, those that estimate probability of one outcomes against others in the choice set, require travel times and costs of each alternative as model inputs. Estimating travel times and costs requires several assumptions on travel speeds, value-of-time, and information on highway tolls and transit fares for each trip outcome, as these models operate under a econometric derived demand framework (Ortúzar \& Willumsen, 2001, p. 220).

The data used are typically from household travel surveys, which provide sociodemographic information about the individual and household, and trip making information. Built environment data are usually compiled from archived spatial databases. Analysts typically quantify several measures of the built environment within geographic buffers around the household, trip origins, or trip destinations and test these measures. These built environment attributes, along with socioeconomics, and trip making characteristics are used as predictors of travel mode choice. 
Built environment measures are characterized in a few common ways. First, and perhaps most abundant, is to use the three "D's", density, diversity, and design (Cervero \& Kockelman, 1997), later expanded to the five D's, which also include destination accessibility and distance to transit (Ewing \& Cervero, 2001). Density reflects concentration of land uses, diversity attributes the mixing and variation of those land uses, design refers to smaller scale measures that reflect the pedestrian friendliness, destination accessibility measures the ease of reaching shopping, employment, and/or services (e.g. distance to central business district, number of jobs within a certain travel time, distance to nearest store), and distance to transit's definition is intuitive. Common other classifications from seminal meta-reviews are land use patterns (e.g. population density, employment density, land use mix), transportation network attributes (e.g. street network connectivity, block size, sidewalk connectivity), and urban design features (e.g. vehicle lane width, sidewalk width, benches, tree canopy) (Ewing \& Cervero, 2001); transportation systems (e.g. gridded vs. dendritic street network), land development patterns (density and land use mix), and micro-scale urban design (e.g. measures of desirability of walking on a particular street) (Frank \& Engelke, 2001).

Due to the high costs and difficulties of longitudinal data collection, data are typically cross-sectional (Bohte, Maat, \& Van Wee, 2009). As such, they allow only for associations to be tested; there is little empirical understanding of causality within the relationships between the built environment, socio-demographics, trip characteristics, and mode choice (Handy, Xing, \& Buehler, 2010). 
More recent attention has been given to the idea of self-selection, the idea that effects of the built environment on travel outcomes are due in part to people with pre-existing preferences to travel by a certain mode or live in areas more amenable to their travel preferences (Mokhtarian \& Cao, 2008). Controls for attitudes and preferences towards neighborhood attributes and travel modes have appeared increasingly since the early 2000s. When attitudes are combined with the built environment in travel models, attitudes are usually significant (e.g. Aditjandra, Cao, \& Mulley, 2012; Ewing \& Cervero, 2001; Kitamura et al., 1997; Mokhtarian \& Cao, 2008). Together, they usually increase overall explanatory power of models over those that do not include attitude measures and allow for interpretation of the effect of the built environment on travel independent of a predisposition in favor of or against particular travel modes. But, attitudes and preferences are not easily included in forecasting models due to difficulty of predicting attitudes in the future and inconsistencies in their measurement (Bohte et al., 2009).

This study, which is cross-sectional, does not imply causality between transportation policies and changes in behavior. Understanding the links between the environment and travel is worthwhile regardless of the direction of influence. For example, if cities install bicycling and walking infrastructure in areas with pre-existing high bike and pedestrian volumes, those investments still improve traveling via those modes. If investments of that kind cause a modal shift in that direction, then the desired outcome is achieved.

\subsubsection{Findings on Mode Choice}

Chatman (2005, p. 169) concludes his $\mathrm{PhD}$ dissertation on non-work travel that, "regardless of pre-existing preferences for walking and transit, people make travel 
choices based on built environment characteristics." In his residential study of 1,114 adults in Alameda, San Francisco, and Santa Clara Counties in California, the author found that the amount of non-work travel made by walking and biking was positively associated with intersection density within $1 / 4$ mile of the residence, that heavy rail within $1 / 2$ mile of the residence increased transit travel, and that increased "network load density," or the number of residents per road mile within one mile of the home, was negatively associated with automobile trips. Chatman did not directly estimate a mode choice framework, but instead tested the effects of neighborhood preferences on neighborhood built environment characteristics and on travel frequencies to reach the conclusion alluding to mode choices.

Steiner (1997) investigated non-work shopping travel by sampling customers at six "traditional" shopping districts in the San Francisco Bay Area. Binary logit models were used to analyze the factors associated with the choice to walk for shopping trips. Choice models for other modes were not estimated. Results showed that travel distance was the largest factor associated with walk mode choice, as well as parking availability at the destination and the shopping district's walking environment, measured as a five-point scale for sidewalk continuity, street crossings, protection from weather, topography, and "other barriers."

Schneider (2011) examined travel to and from shopping districts as well. The author used two mixed logit models to examine mode choices for (1.) the trip to and from shopping districts and (2.) the overall tour, including intermediate trips within the shopping districts. The first model examined walk, transit, and automobile mode choices of 388 
travelers at 20 retail pharmacy stores in the San Francisco Bay Area. Bicycling was not included in the choice set because of few observations of cyclists in the sample. The estimation controlled for travel characteristics, socio-demographics, mode-specific attitudes, and characteristics of the built environment at the shopping establishment. Results indicated a negative relationship between employment density in the shopping district and automobile mode choice and a positive relationship between population density and walk and transit mode choices. Parking availability was positively associated with automobile mode choice as well. The author also found that certain sociodemographic traits affect mode choices. The second model to predict the overall tour mode choice used a larger sample of 959 travelers and included bicycle choice. These results showed that at the establishment end of the trip, employment density was negatively associated with automobile choice, population density was positively associated with walk and transit mode choices, bike facilities provision increased the odds of bike mode choice, and vehicle parking was positively associated with automobile mode choice. Tour distance had a significant negative association with walk mode choice and to a lesser extent bike mode choice. Few demographic characteristics were significant in this model, but one stands out: a zero-car household was the biggest detractor to automobile mode choice.

Frank et al. (2008) analyzed mode choice with a multinomial logit model. They controlled for built environment characteristics at origins and destinations, demographics, travel times and costs, and tour complexity. The analysis of 14,487 travelers in the Puget Sound Region did not control for attitudes or self-selection. Findings for the non-work model showed that walk mode choice was influenced by land use mix, intersection 
density, and retail floor-area ratio — a measure that represents retail density—at the origin and retail floor-area ratio at the destination. Bike mode choice was associated with intersection density at the origin. Transit mode choice was associated with land use mix and intersection density surrounding the home, and the same two measures as well as retail floor-area ratio at the destination.

Rajamani et al. (2003) estimated a multinomial logit non-work travel mode choice model using data from a 1995 Portland, Oregon regional household activity survey. The travel mode alternatives of carpool, drive alone, transit, walk, and bicycle were compared with carpool as the base case. The estimation controlled for demographic characteristics, travel costs, and urban form. The authors found that socio-demographics had strong effects on mode choices. Increased vehicles per adult in the household was a strong detractor from walk and bicycle mode choices and more adults per household reduced the probability of walk mode choice. Increased age showed a higher likelihood of carpooling, and physical handicap predicted a reduced choice of driving alone. The analysis also showed that built environment independently affects mode choice. Land mix diversity supported walk mode choice, but did not alter other travel choices significantly from the carpool base case. Population density was negatively associated with choosing to drive and positively associated with choosing transit. The percentage of cul-de-sacs, a proxy variable for street connectivity and housing mix, was negatively associated with the choice to walk. The authors also calculated elasticities that showed ethnicity had the strongest association with walking, and vehicles per adult in the household to be the strongest predictor of bicycling mode choice. 
Zhang (2004) estimated a multinomial logit mode choice model for Boston household travel survey data and a nested logit mode choice model for Hong Kong household travel survey data. Two sets of home-based trip choice models, for work and non-work travel, were estimated for each city. The Boston non-work model results showed that built environment characteristics significantly affected mode choices. Higher population densities at trip destinations were associated with higher probabilities of transit, walking, and bicycling mode choices, the percentage of cul-de-sacs at the trip destination was positively associated with the choice to drive alone, and the land use balance at the destination - an Entropy measure-was associated with higher likelihood of a nonautomobile mode choice. The Hong Kong non-work model showed that population density at the origin had a small positive association with transit choice and that employment density at the destination had a small negative relationship with driving. Socio-demographics were also important to certain mode choices. In the Boston model, people under 30 years of age were more likely to walk or bike and increased vehicles per worker in the household predicted higher likelihood of drive or carpool mode choice. In the Hong Kong model, age under 30 and being a female without small children predicted higher probability of transit mode choice, and vehicles per person in the household predicted a much higher probability of driving. The study showed that the built environment independently explained a significant amount of the variation in mode choices.

Van Acker et al. (2011) used structural equations models to predict non-work mode choices of 1,878 internet travel survey respondents in Flanders, Belgium. Their models predicted mode choice based on personal characteristics, lifestyles, car availability, 
attitudes toward the built environment and travel, and objective built environment measures surrounding the residence. They found that the built environment, measured through factor analysis as "location relative to local centre," "location relative to regional centre," local accessibility, regional accessibility, and density, had a large influence on

mode choice in the expected directions: negative for car choice, positive for transit choice, and positive for cycling and walking choice. Car availability was the most significant determinant of mode choice. Results also showed that the built environment's impact on travel is increased when attitudes are included in models, but the authors describe that with such a complex model structure it is difficult to say if either objective or attitudinal measures of the built environment are more important in predicting travel. Also, as is common in other studies, the authors combined the bicycle and walk mode choice alternatives together. This thesis will show in Chapter 4 that these two nonmotorized modes have distinct characteristics and that their combination in analysis should be avoided.

\subsubsection{Findings Summary}

Findings among studies have been somewhat mixed in the details, but built environment attributes tend to consistently have a moderate impact on non-work mode choice. There is little consistency across studies on which specific built environment attributes are controlled for in analysis models. This is due to the fact that many built environment measures are usually highly correlated with one another (Clifton, Muhs, et al., 2013; Handy et al., 2002). To deal with this issue, some studies used factor analysis or index measures that combine many built environment attributes into one variable, but these are more difficult to interpret in analysis models. 
The most important built environment variables related to non-work mode choice are the same as outlined in meta-reviews of general travel behavior and built environment studies. $^{2}$ Variables measuring residential density, employment density, mixed land uses, a friendly pedestrian environment, transit accessibility, and mode-specific features of the transportation network are consistently associated with travel choices. Other consistently associated variables include vehicle ownership or availability, trip distances, socioeconomics and demographics, and attitudes, when measured.

\subsection{Approach and Contribution}

As guided by existing literature, this study examines travel mode choices at the individual level through binary logit models that will be explained in the following chapters. A multinomial logit model is not used because the estimation of travel time and cost parameters was deemed early on as complex, given the establishment-based orientation of the dataset. Further, the binary logistic regression framework used allows for models that control for variables specific to each travel mode. For example, in the binary bicycle mode choice model, we control for bike-specific attributes that would not be pertinent in an automobile mode choice model. We also control for mode-specific attitudes to examine the effects of the built environment independent of self-selection.

The variables used in the research correspond to those in existing work. Specifically, we account for individual and household characteristics, including vehicle availability, trip characteristics including distance and type, and the built environment, with population density, employment density, intersection density, housing mix, lot coverage, and

\footnotetext{
${ }^{2}$ To the author's knowledge, no meta-reviews on studies of the built environment and non-work travel mode choices are currently available.
} 
distance to rail transit incorporated into a factor analysis. Travel mode-specific variables are included when relevant as well.

The data used here for analysis were collected as a destination-based travel survey, unlike a household-based travel survey upon which most of the travel and built environment literature is based. This offers a unique perspective to analyze the characteristics involved with travel choices. Household travel surveys usually do not have enough responses from participants at the same trip destinations to analyze the factors at the destination end of the trip. The data used here allow detailed analysis of the destination-end characteristics to be included in the choice analysis. We also analyze data from two points of analysis, the individual choice and the establishment mode share, offering another contribution to the literature. Finally, more destination-end land uses are controlled for than in Schneider's (2011) similar analysis of travel choice at pharmacy retail stores. The data and analysis methods are presented in the next chapter. 


\section{Chapter 3. Data and Methods}

The aim of this research is to examine the following different aspects of travel behavior: 1.) the relationships between travel choices and the built environment at the individual level, 2.) the differences of these relationships across travel modes, 3.) the comparisons of built environment impacts at the individual choice level and at the establishment mode share level, 4.) how personal characteristics impact mode choices, and 5.) what the overall key differences are of comparing results at two different analysis levels using the same data. To execute this approach, data from a 2011 trip generation study in Portland, Oregon are used.

Data were first collected through travel intercept surveys conducted at convenience stores, restaurants, and bars, then augmented with archived spatial data. In this chapter, an overview of data collection and a summary are provided. First, the site selection, survey instrument, and survey methodology are discussed. Then, the built environment data are introduced along with presentation of a factor analysis for built environment variables. Finally, a sample description is provided for individual-level data and establishment-level data. In this paper, we use the term "aggregate" level to describe establishments in the study dataset and location-oriented analysis. The term "disaggregate" refers to individual-oriented analysis and data.

\subsection{Travel Intercept Survey}

\subsubsection{Site Selection}

Between June and October 2011, intercept surveys were administered to customers at convenience stores, high-turnover sit down restaurants, and bars. These three land uses 
are chosen because they are abundant across the region in different urban contexts and their price points are consistent across the region. The term "convenience store" refers to small markets with no gas station attached. Customers typically purchase small quantities of items like snacks, drinks (both non-alcoholic and alcoholic), cigarettes, and lottery tickets. "High-turnover sit down restaurants" in the sample are pizza and Mexican restaurants that had seating where meals were typically under $\$ 15$. Take-out and delivery are common options at these places. "Bars" refer to drinking places and brew pubs serving alcohol. In Oregon, establishments that serve beer usually have to provide a food menu as well, so many of these establishments function somewhat like a restaurant.

Most of the establishments in the study are regionally owned chains. These businesses were more willing to participate than national chains. This introduces some bias in the sample because locally owned stores may cater to different market segments than the patrons of national stores, and local restaurant chain stores are generally smaller in size than those of national chains.

The 78 establishments included in the study represent a variety of urban neighborhood types and spanned across the region. A map of the establishments is shown in Figure 3-1. More sites are located in the city center and the inner east side of Portland because urban context varies more in these neighborhoods than in the suburbs and on the urban fringe. 


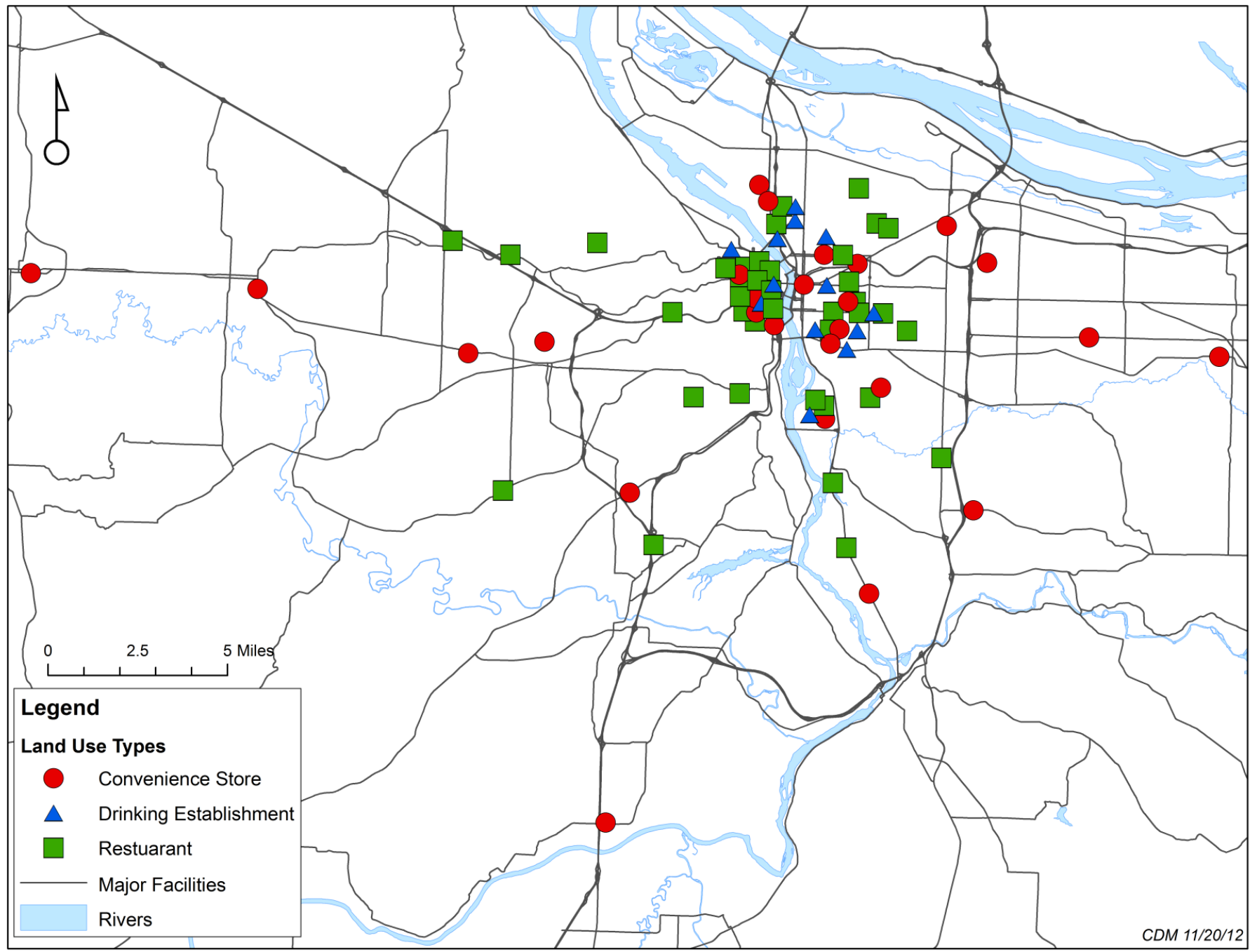

Figure 3-1. Locations of Survey Establishments 


\subsubsection{Survey Method \& Instrument}

Intercept surveys were administered to customers exiting restaurants, convenience stores, and bars by university students. A five minute questionnaire on computer tablets was offered initially. A printed version can be found in Appendix A. This "long survey" collected information on:

- Travel modes from previous location to establishment and from establishment to next destination

- Amount of time and money spent

- How frequently they visit the establishment

- Attitudes towards the use of transportation modes at the establishment

- Demographics and characteristics of respondent and household

- Map locations of home, work, origin, and next destination

If the customer refused to take the electronic survey, they were then offered a 30 second "short survey" consisting of four questions: 1) travel mode from previous location, 2) dollar amount spent, 3) frequency of travel to establishment, and 4) home address or nearest intersection to home. Gender was recorded by the survey administrator. This survey instrument is available in Appendix B.

To control for weather, surveys were only administered for these establishments on days with favorable conditions, i.e. no rain. Data collection occurred from 5:00 PM to 7:00 PM on Mondays, Tuesdays, Wednesdays, and Thursdays. 
On average, 8.9 long surveys and 15.2 short surveys were collected at each establishment. The response rate for long surveys was $19 \%$ and for long and short surveys combined was $52 \%$. Table $3-1$ shows more detail on the sample size.

Table 3-1. Convenience Store, Restaurant, and Bar Survey Sample Size

\begin{tabular}{lcccccc}
\hline & & & & \multicolumn{2}{c}{ Response Rates } & \\
\multicolumn{1}{c}{ Land Use } & $\begin{array}{c}\text { Establishments } \\
(\mathbf{N})\end{array}$ & $\begin{array}{c}\text { Long } \\
\text { Surveys (N) }\end{array}$ & $\begin{array}{c}\text { Short } \\
\text { Surveys (N) }\end{array}$ & $\begin{array}{c}\text { Long } \\
\text { Survey }\end{array}$ & $\begin{array}{c}\text { Short and } \\
\text { Long } \\
\text { Survey }\end{array}$ & Total \\
\hline Drinking places & 13 & 107 & 108 & $30 \%$ & $50 \%$ & 215 \\
Convenience & 26 & 281 & 710 & $14 \%$ & $61 \%$ & 991 \\
Restaurants & 39 & 309 & 369 & $24 \%$ & $52 \%$ & 678 \\
\hline Total & 78 & 697 & 1187 & $19 \%$ & $52 \%$ & 1884 \\
\hline
\end{tabular}

\subsection{Built Environment Data}

Built environment information was gathered directly from the establishment sites (see Appendix C) or assembled from archived data sources. The archived information was compiled using a half-mile radius (Euclidean distance) surrounding each establishment location. ${ }^{3}$ The measures that were included in this study are described in detail below.

Several built environment features that influence travel choices that have been identified in the literature as influential are considered in analysis. Some mode-specific attributes are also considered to measure amenities for walking and bicycling. Neighborhood-level built-environment characteristics are assembled from U.S. Census Bureau files and from RLIS (Regional Land Inventory System), the geographic data library for Metro, the regional government agency for the Portland area. The built environment variables are defined below in Table 3-2 and averages for the sample of business establishments included in this study are summarized in Table 3-3.

\footnotetext{
${ }^{3}$ Water features were excluded from all calculations when water fell within the half-mile buffer
} 
Table 3-2. Built Environment Measures and Sources

\begin{tabular}{|c|c|c|c|}
\hline Measure & Units & Data Source* & $\operatorname{Note}(s)$ \\
\hline Population density & Residents per acre & $\begin{array}{l}\text { Multifamily/Household } \\
\text { layers (RLIS, 2010) }\end{array}$ & \\
\hline Employment density & Employees per acre & $\begin{array}{l}\text { ESRI Business Analyst } \\
\text { (2010) }\end{array}$ & \\
\hline Activity density & People per acre & $\begin{array}{l}\text { Multifamily/Household } \\
\text { layers (RLIS, 2010) }\end{array}$ & Combination of population and employment densities \\
\hline Lot coverage & $\begin{array}{l}\text { Percent tax-lot parcel } \\
\text { area covered by building } \\
\text { footprints }\end{array}$ & $\begin{array}{l}\text { Tax lot and building layers } \\
\text { (RLIS, 2010) }\end{array}$ & Proxy for parcel setbacks and density of development \\
\hline $\begin{array}{l}\text { Distance to rail } \\
\text { station }\end{array}$ & Miles & Rail stop layer (RLIS, 2010) & Includes light rail and streetcar stops \\
\hline Intersection density & \# Intersections & Lines file (TIGER 2009) & \\
\hline Housing type mix & Percent single family & $\begin{array}{l}\text { Household layer (RLIS, } \\
\text { 2010) }\end{array}$ & Measures diversity of housing within buffer \\
\hline $\begin{array}{l}\text { Quantity of low } \\
\text { stress bikeways }\end{array}$ & Lane miles & $\begin{array}{l}\text { Bike route layer (RLIS, } \\
2010 \text { ) }\end{array}$ & $\begin{array}{l}\text { Includes multiuse paths, enhanced bike lanes, cycletracks, bike } \\
\text { boulevards, low-traffic streets, and streets with bike lanes and speeds } \\
\text { under } 35 \mathrm{mph}\end{array}$ \\
\hline
\end{tabular}




\begin{tabular}{|c|c|c|c|}
\hline Measure & Units & Data Source* & $\operatorname{Note}(s)$ \\
\hline Parking lot & Binary & Site visits & $\begin{array}{l}\text { Parking lot exclusive to the site or shared with an adjacent or nearby } \\
\text { business }\end{array}$ \\
\hline $\begin{array}{l}\text { Establishment is in } \\
\text { shopping center }\end{array}$ & Binary & Site visits & $\begin{array}{l}\text { Shopping centers defined as strip mall-type developments with at least } \\
\text { three stores; different from urban shopping districts }\end{array}$ \\
\hline $\begin{array}{l}\text { Length of "high- } \\
\text { traffic" bike } \\
\text { facilities }\end{array}$ & Miles & $\begin{array}{l}\text { Bike route layer (RLIS, } \\
\text { 2010) }\end{array}$ & $\begin{array}{l}\text { Classified as roads with bike lanes and posted speed limits greater than } 35 \\
\text { miles per hour }\end{array}$ \\
\hline $\begin{array}{l}\text { Distance to nearest } \\
\text { "low-traffic" street }\end{array}$ & Miles & $\begin{array}{l}\text { Bike route layer (RLIS, } \\
2010)\end{array}$ & $\begin{array}{l}\text { Classified as streets with no designated bikeway and posted speeds less } \\
\text { than } 25 \mathrm{mph}\end{array}$ \\
\hline $\begin{array}{l}\text { Presence of bike } \\
\text { corral }\end{array}$ & Binary & Site visits & $\begin{array}{l}\text { Measured within } 200 \mathrm{ft} \text { of establishment. A bike corral typically has six to } \\
12 \text { bicycle racks in a row, often replaces on-street automobile parking and } \\
\text { can park } 10 \text { to } 20 \text { bicycles, and the space is otherwise occupied by one to } \\
\text { two cars }\end{array}$ \\
\hline $\begin{array}{l}\text { Number of bicycle } \\
\text { parking spots }\end{array}$ & Number of parking spots & Site visits & $\begin{array}{l}\text { Measured on the street immediately serving the establishment and the } \\
\text { adjacent street; calculated for the number of bicycles that could be parked } \\
\text { (i.e., a bike parking staple has two bike parking spots) }\end{array}$ \\
\hline
\end{tabular}

Note: unless otherwise specified, all variables measured within 0.5 miles of establishment

* RLIS: Regional Land Information System, Portland Metro. 


\section{Table 3-3. Average Site Characteristics of Establishments}

\begin{tabular}{|c|c|c|c|c|}
\hline Site attribute & $\begin{array}{c}\text { Convenience } \\
\text { Stores } \\
\mathbf{N}=\mathbf{2 6} \\
\end{array}$ & $\begin{array}{c}\text { Bars } \\
\mathbf{N}=13 \\
\end{array}$ & $\begin{array}{c}\text { Restaurants } \\
\mathbf{N}=\mathbf{3 9}\end{array}$ & $\begin{array}{c}\text { All } \\
\mathrm{N}=78 \\
\end{array}$ \\
\hline Population density (people per acre) & 11.9 & 13.6 & 15.0 & 13.8 \\
\hline Employee density (employees per acre) & 16.0 & 27.3 & 22.0 & 20.9 \\
\hline Activity density (people per acre) & 27.9 & 41.0 & 36.3 & 34.3 \\
\hline Lot coverage $(\%)$ & $25 \%$ & $33 \%$ & $29 \%$ & $28 \%$ \\
\hline Distance to rail (mi) & 1.7 & 1.1 & 1.4 & 1.5 \\
\hline Intersection density (\# intersections) & 151 & 207 & 173 & 171 \\
\hline$\%$ Single family housing & $46 \%$ & $43 \%$ & $43 \%$ & $44 \%$ \\
\hline Quantity of low-stress bikeways (mi) & 2.0 & 2.3 & 2.3 & 2.2 \\
\hline Parking lot & $96 \%$ & $31 \%$ & $54 \%$ & $64 \%$ \\
\hline Establishment is in a shopping center & $12 \%$ & $0 \%$ & $33 \%$ & $21 \%$ \\
\hline $\begin{array}{l}\text { Length of "high-traffic" bike facilities } \\
\text { within } 0.5 \text { miles }\end{array}$ & 0.86 & 1.27 & 1.34 & 1.17 \\
\hline $\begin{array}{l}\text { Distance to nearest "low-traffic" bike } \\
\text { facility(mi) }\end{array}$ & 0.20 & 0.13 & 0.24 & 0.21 \\
\hline Presence of bike corral within 200 feet & $12 \%$ & $38 \%$ & $8 \%$ & $14 \%$ \\
\hline Bike parking spots & 2.5 & 22.5 & 7.3 & 8.2 \\
\hline
\end{tabular}

Restaurants and bars tend to be located in areas with the highest population and employment densities, on average, and have the most bike corrals. Average distance to rail, intersection density, and miles of low stress bikeways are all similar across establishment types.

The various built environment factors identified as most influential in the travel behavior literature are highly correlated. Places of high population and employment density also have good transit access, diverse mixing of housing and land use types, and pedestrian- 
friendly environments. Table 3-4 shows Pearson correlations $(r)$ between the main built environment factors related to travel from the literature for the 78 establishments in this study. All of the measures are significantly correlated at $99.9 \%$ confidence. The high correlations between the measures cause multicollinearity issues in regression analysis models, so in the following section a factor analysis is conducted to reduce the dimensionality of these data to bypass this problem.

Table 3-4. Correlations between Built Environment Measures

\begin{tabular}{|c|c|c|c|c|c|c|}
\hline Built Environment Measure & & 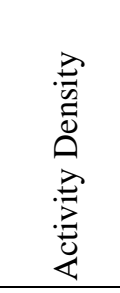 & 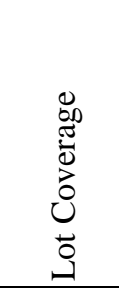 & 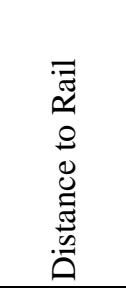 & 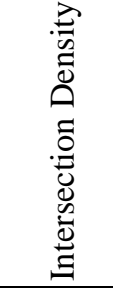 & $\begin{array}{l}\sum_{\infty}^{x} \\
.0 \\
.0 \\
0 \\
0\end{array}$ \\
\hline Activity Density & $r$ & & & & & \\
\hline Lot Coverage & $r$ & $0.85^{*}$ & & & & \\
\hline Distance to Rail & $r$ & $-0.39 *$ & $-0.41 *$ & & & \\
\hline Intersection Density & $r$ & $0.63^{*}$ & $0.83^{*}$ & $-0.46^{*}$ & & \\
\hline Housing Mix & $r$ & $-0.74 *$ & $-0.67 *$ & $0.31 *$ & $-0.44^{*}$ & \\
\hline
\end{tabular}

*significant at $\mathrm{p}<0.01$

\subsection{Factor Analysis}

Factor analysis is a data dimensionality reduction tool that takes sets of interrelated variables and extracts a small number of underlying factors. The factors in turn represent the relationships between the interrelated variables (for more on factor analysis, see: Joliffe, 1986; Afifi, Clark, \& May, 2004; for examples, see: Cervero \& Kockelman, 1997; Handy, Cao, \& Mokhtarian, 2005). Factor analysis allows for more simple models and can help identify relationships within but not apparent in the data. The analysis technique is useful for multiple regression when many variables-e.g. intersection 
density, access to transit, or activity density — are highly correlated and are measuring aspects of the same underlying object — the built environment in this case-because the extracted factor(s) can be used in regression to represent the underlying variables. However, when factors are used in regression models, interpretation of regression coefficient estimates becomes abstract.

A factor analysis is used in this research to combine several measures of the built environment into a single variable. The Varimax rotation was used in the SPSS FACTOR procedure. This single factor allows the spectrum of the built environment to be represented in regression analysis while bypassing multicollinearity problems that would arise if individual built environment variables were analyzed together in the same regression analysis.

The factor loadings are shown in Table 3-5. People density, intersection density, and percent lot coverage all have positive contributions to the factor. Percent single family housing and distance to light rail have negative contributions to the factor. A scree plot is shown in Figure 3-2. The scree test, or visually examining where the bend in the scree plot occurs, is the best choice for deciding the number of factors to retain in a factor analysis (Costello \& Osborne, 2005). There is a steep decline in eigenvalue after one component and the bend in the plot at the second factor confirms that retaining one factor through the scree test is acceptable. The single factor explains $67 \%$ of the variation across individual built environment variables.

In the built environment factor analysis used here, different categories (e.g. density variables and diversity variables) of built environment measures are combined together. 
Unlike some of the previous work in travel behavior research where factors were developed for different categories of built environment measures (e.g. Cervero \& Kockelman, 1997; Handy, Cao, \& Mokhtarian, 2005), variables here are combined into one single factor that is an indicator for the level of overall urbanism of the survey establishments.

\section{Table 3-5. Factor Loadings for Built Environment}

\begin{tabular}{lr}
\hline Built Environment Variable & Factor loading \\
\hline Activity density & 0.906 \\
Intersection density & 0.835 \\
Lot coverage & 0.944 \\
Percent single-family housing & -0.782 \\
Distance to light rail station & -0.578 \\
\hline Percent of variance explained & $67.1 \%$ \\
\hline
\end{tabular}




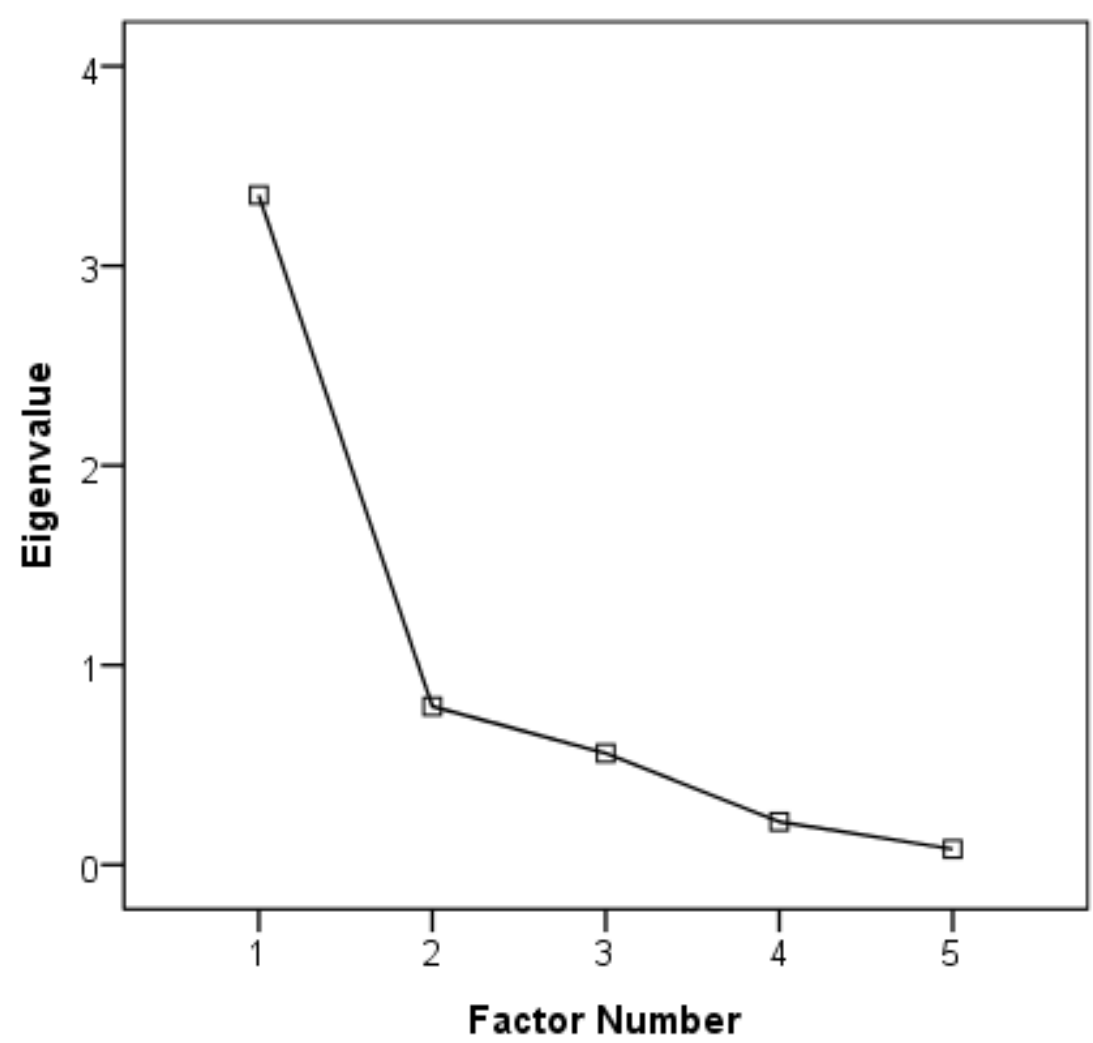

Figure 3-2. Scree Plot for Built Environment Factor Analysis

The differences in the resulting built environment factor variable may be difficult to interpret, particularly in regression models in the next chapter when regression coefficients correspond to a one unit increase in the variable. To aid in interpretation, photos and descriptions are provided here for values of $-1,0$, and 1 . The values of the factor analysis output are standardized, so a value of zero corresponds to a representation of the "average built environment" of the sample. Values of negative and positive one equate to sites with one standard deviation below and above what constitutes the "average built environment" in the sample. 
An example of a site with one standard deviation below the average is shown in Figure 3-3. ${ }^{4}$ There is bus service present and a striped bike lane on one of the adjacent streets, but the nearby neighborhoods are homogenous single family detached homes and businesses are all one story in height. Sites have setbacks from the roadway and car parking lots in front of the store entrances.

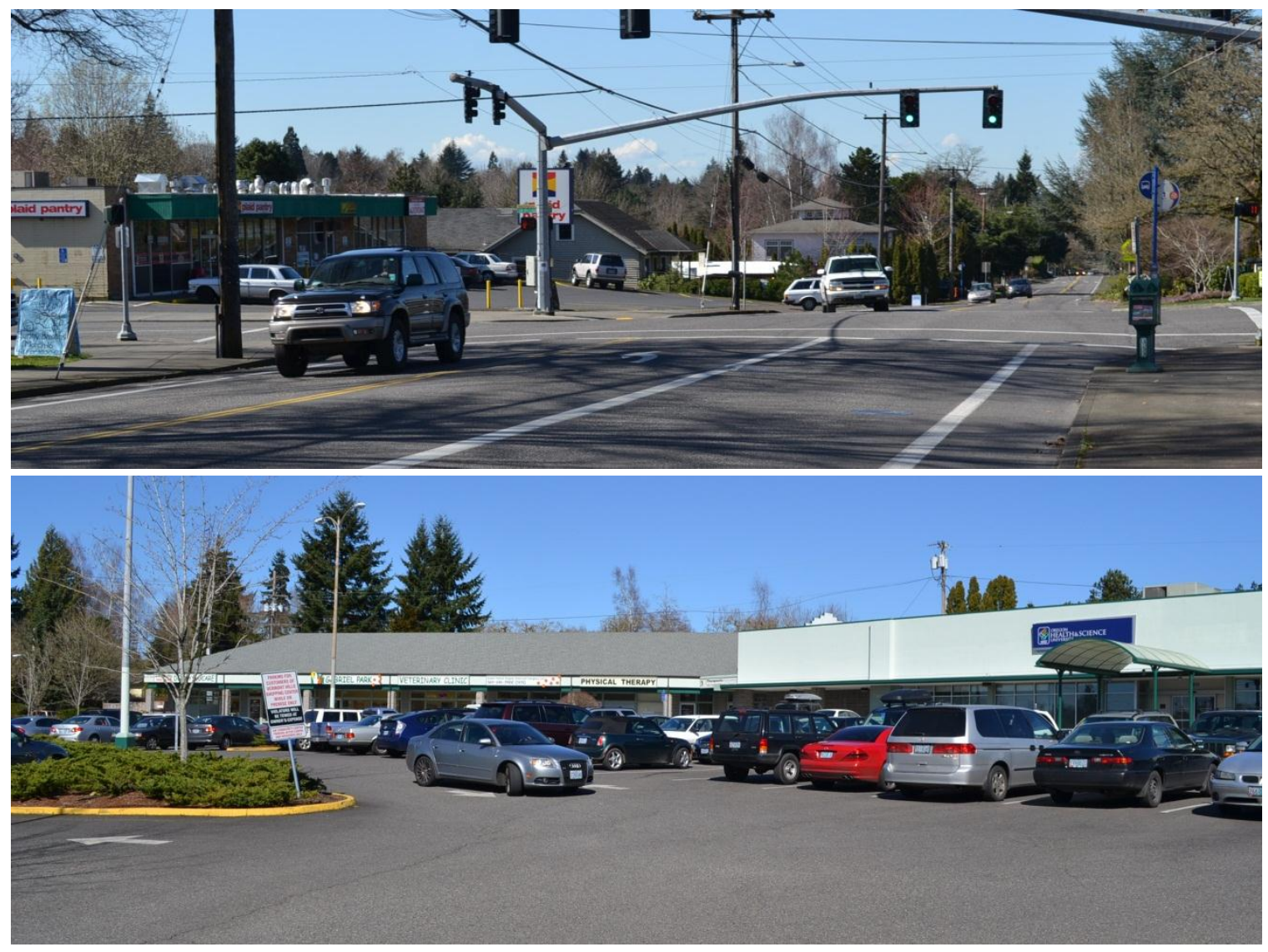

Figure 3-3. Example of Built Environment Factor $=-1$

Figure 3-4 shows photos of a site with a built environment factor value close to zero. ${ }^{5}$ Although located on a four lane arterial, the nearby streets are quiet, low-traffic, and

\footnotetext{
${ }^{4}$ This site had a built environment factor $=-1.09$.

${ }^{5}$ This site had a built environment factor $=-0.02$.
} 
residential. A neighborhood bikeway —a street with traffic calming features, bicycle wayfinding signage, and painted bicycle sharrows on the pavement - is two blocks away. Apartments and several other businesses are nearby. A moderate amount of buildings are two stories or more. Businesses front the sidewalk, bike parking is usually available in front of or close to all stores, and on-street car parking is present.

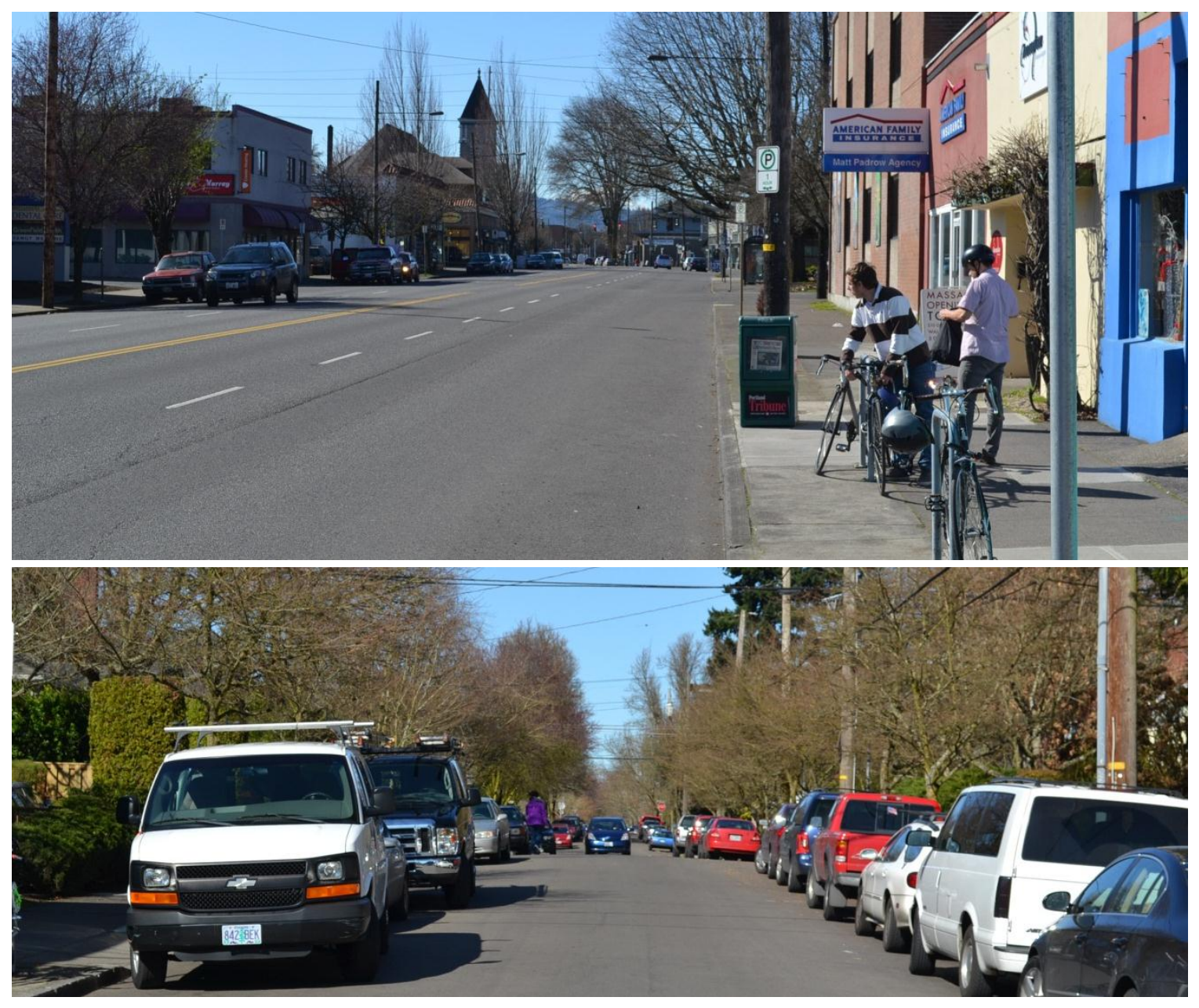

Figure 3-4. Example of Built Environment Factor = 0 
An example of a site with a built environment factor value close to one ${ }^{6}$ is shown in Figure 3-5. The site is located in a retail shopping district close to downtown. Streetcar and bus serve the site, there is a high mix of housing types, a dense gridded street network, many buildings are three stories or more in height, comfortable bicycling facilities are nearby, and most buildings front the main street.

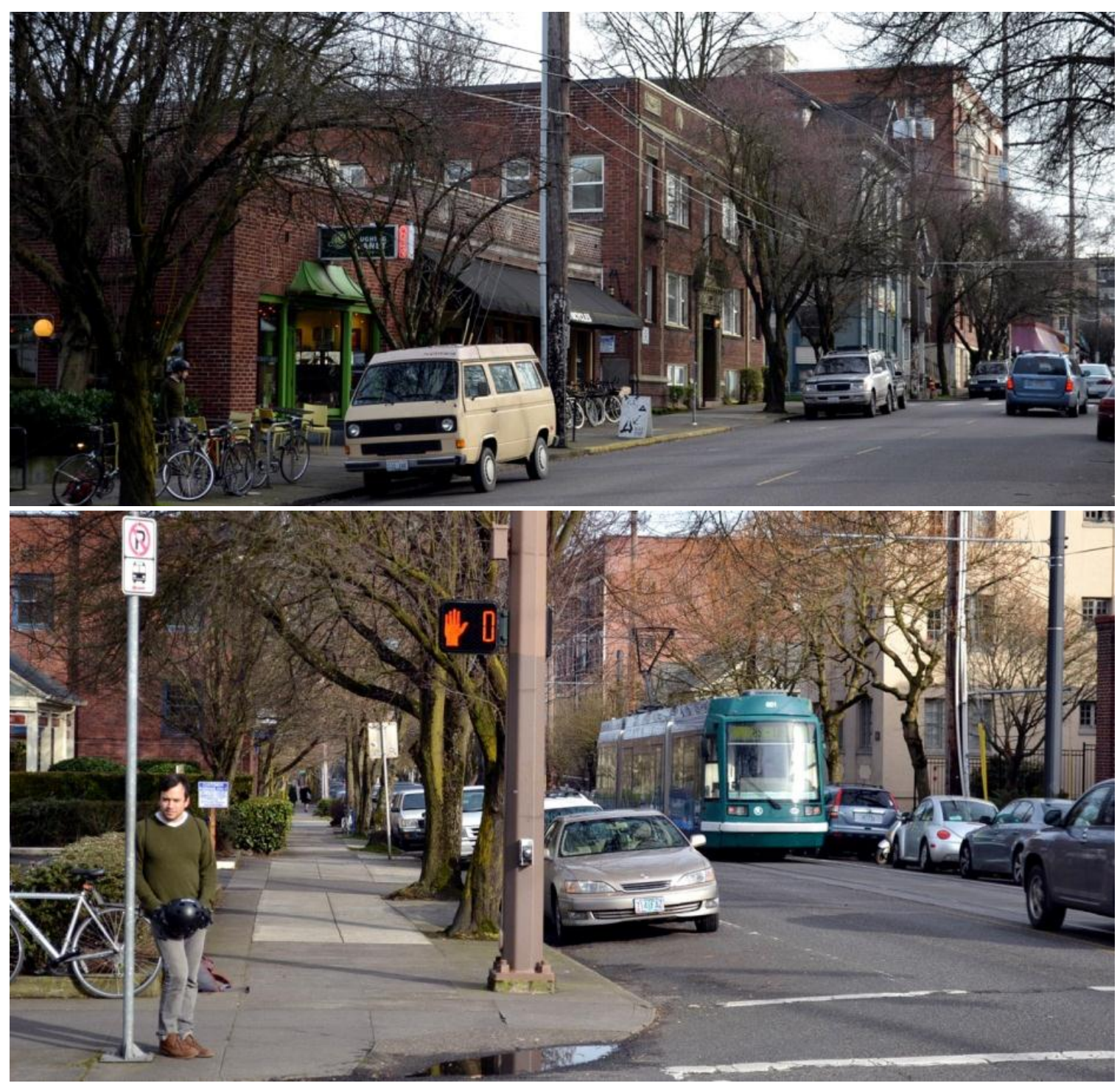

Figure 3-5. Example of Built Environment Factor = 1

\footnotetext{
${ }^{6}$ Actual value $=1.05$.
} 


\subsection{Sample description}

This section describes individual and establishment data collected. For details on how data were prepared for analysis, see Appendix D.

\subsubsection{Individual-level data}

Demographic characteristics, trip characteristics, and attitudes of long survey respondents are shown in Table 3-6. Long survey data are displayed here because short survey data do not include customer demographic information other than gender. Overall, 7\% of respondents had a physical limitation that prevented walking, bicycling, or driving. Average income was $\$ 68,530$, and more men were surveyed than women. The average age was 37 and $49 \%$ of the sample was over 34 . Of the households, $85 \%$ owned at least one vehicle and $28 \%$ had at least one child.

Regarding the trip characteristics of respondents, $82 \%$ of trips to the establishment were home-based (either came from or went to the home). $23 \%$ of trips observed were workbased. The average group size, recorded as "how many people in your group did this purchase pay for," was 1.64. Average trip length from origin to establishment was 3 miles.

In general, respondents tended to have more positive attitudes towards the use of individual travel modes than negative ones. ${ }^{7}$ Between $60 \%$ and $79 \%$ of people in the sample had positive attitudes towards use of one or more of the travel modes, and

\footnotetext{
${ }^{7}$ It is important to note that the attitude evaluation statements (see Appendix A, Q11) asked the respondents to evaluate their feelings towards using a particular mode at the particular establishment, and not their general feelings towards that mode. For example, we had respondents evaluate the statement "walking here is safe and comfortable" and not "I like to walk."
} 
between $9 \%$ and $22 \%$ of people had negative attitudes towards one or more of the travel modes.

\subsubsection{Establishment-level data}

Figure 3-6 shows the observed mode shares by each establishment type. ${ }^{8}$ The automobile is clearly the dominant mode for customers across all establishments and transit is the least used mode. Drinking places have the lowest automobile mode share of the four business types surveyed. Only $43 \%$ of patrons arrive by automobile.

Of the non-automobile modes, walking has the highest mode share across land uses. Walking rates are highest for convenience stores and drinking places, both with $27 \%$ mode share. Restaurants have a $22 \%$ walk mode share. Bicycling is most popular at bars, where $22 \%$ of patrons arrive by bike. Restaurants and convenience stores have $8 \%$ and $7 \%$ bike mode share. Transit use is fairly consistent across convenience stores (6\%), restaurants $(6 \%)$ and drinking places $(7 \%)$.

${ }^{8}$ Calculated from long and short surveys at establishments. 


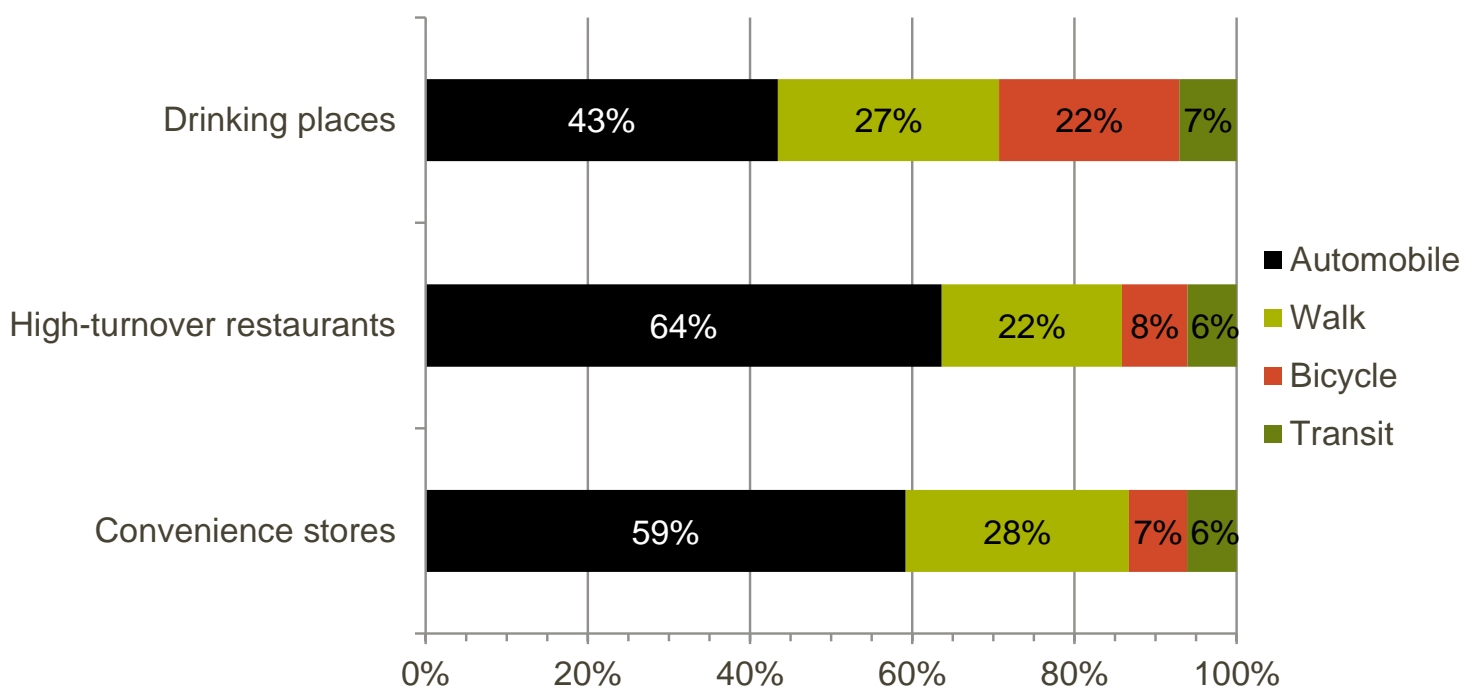

Figure 3-6. Observed Mode Share

Figure 3-7 shows the mode shares for all establishments surveyed in a spatial context. ${ }^{9}$ Automobile mode shares are generally lower in establishments closer to the city center. There is variation in automobile mode share in the inner east side of Portland where neighborhoods transition from urban to suburban. Establishments located near light rail and streetcar lines generally have higher transit mode shares than sites that are not.

\footnotetext{
${ }^{9}$ Calculated from long and short surveys at establishments.
} 


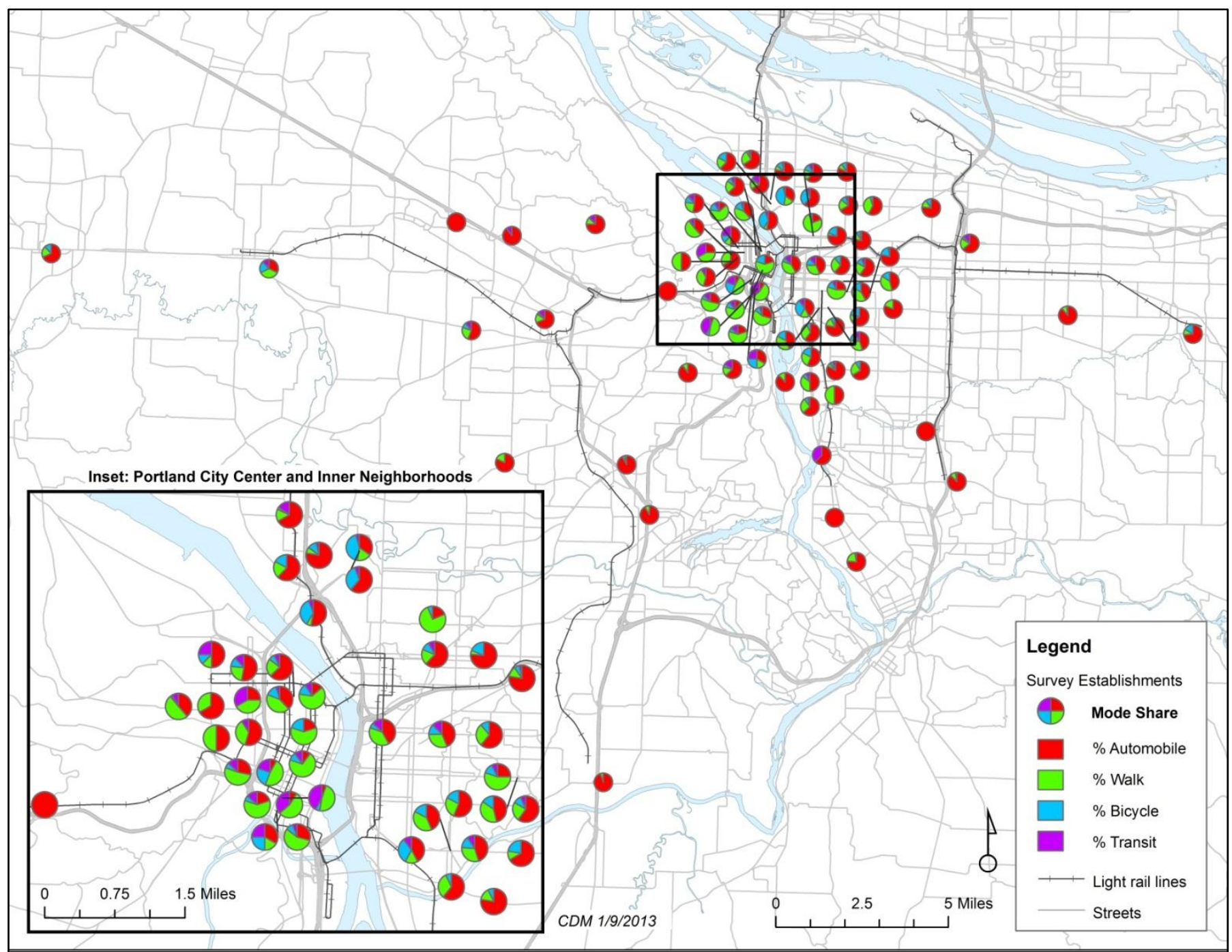

Figure 3-7. Mode Share Map of Survey Establishments 
Table 3-7 summarizes site-level data collected. The socio-demographics and trip characteristics are aggregations of long survey responses. ${ }^{10}$ Two establishments recorded zero responses to the long survey and are not represented in the table. Mode shares use information gathered from short and long surveys. The built environment data was introduced previously in section 3.2, but here the descriptives from the factor analysis are shown.

Establishments saw walk mode shares between zero and $75 \%$, with an average of $25 \%$. Bike mode shares were between zero and $42 \%$, with an average of $9 \%$. Automobile mode share averaged $58 \%$ with a low of $5 \%$ and a high of $100 \%$.

Averages observed at the establishments for socio-demographics and trip characteristics are slightly different than the individual sample (e.g. income, vehicles in household, child in household, trip distance) because the differing number of observations obtained at each establishment.

The built environment factor has a mean of zero with a standard deviation of one because the factor analysis calculation standardizes the variable. Establishments with the highest built environment factor were located in downtown Portland and the Pearl district, a neighborhood adjacent to downtown that has undergone much urban renewal since the 1990s and has many high-rise condominiums, retail shops, art galleries, and restaurants in high density and mixed use infill developments. Establishments with the lowest built environment factor values were located in car-oriented shopping centers in the suburbs.

\footnotetext{
${ }^{10}$ Socio-demographic information, with the exception of gender, was not collected in the short survey. The average gender (\% male) calculation at the establishment was not performed using both datasets to avoid confusion.
} 
Table 3-6. Individual Characteristics from Long Survey Sample

\begin{tabular}{|c|c|c|c|c|c|c|}
\hline Variable & Description & $\mathrm{N}$ & Mean & S.D. & Min & Max \\
\hline \multicolumn{7}{|l|}{ Socio-demographics } \\
\hline Phys. limitation & Physical limitation that prevents walking, bicycling, or driving (binary) & 694 & 0.07 & 0.25 & 0 & 1 \\
\hline Income & Income, in $\$ 10,000$ s & 695 & 6.85 & 5.89 & 1.25 & 25.00 \\
\hline Gender & Gender (binary, $1=$ Male) & 695 & 0.57 & 0.50 & 0 & 1 \\
\hline Age $35+$ & Age 35 or older (binary) & 696 & 0.49 & 0.50 & 0 & 1 \\
\hline Vehicle in $\mathrm{HH}$ & At least one vehicle in household (binary) & 681 & 0.85 & 0.36 & 0 & 1 \\
\hline Child in $\mathrm{HH}$ & At least one child in household (binary) & 697 & 0.28 & 0.45 & 0 & 1 \\
\hline \multicolumn{7}{|l|}{ Trip characteristics } \\
\hline Home-based trip & Origin before establishment or destination after establishment was home (binary) & 697 & 0.82 & 0.38 & 0 & 1 \\
\hline Work-based trip & Origin before establishment or destination after establishment was work (binary) & 697 & 0.23 & 0.42 & 0 & 1 \\
\hline Group size & Group size of the purchase at establishment & 688 & 1.64 & 0.91 & 1 & 5 \\
\hline Distance & Trip distance, origin to establishment (miles) & 664 & 3.00 & 3.95 & 0.00 & 25.60 \\
\hline \multicolumn{7}{|l|}{ Attitudes } \\
\hline Car parking - positive & Positive response to "car parking here is easy \& convenient" (binary) & 648 & 0.56 & 0.50 & 0 & 1 \\
\hline Walking - positive & Positive response to "walking here is safe \& comfortable" (binary) & 673 & 0.79 & 0.41 & 0 & 1 \\
\hline Bicycling - positive & Positive response to "bicycling here is safe \& comfortable" (binary) & 616 & 0.56 & 0.50 & 0 & 1 \\
\hline Bike parking - positive & Positive response to "bike parking here is easy \& convenient" (binary) & 622 & 0.68 & 0.47 & 0 & 1 \\
\hline Transit - positive & Positive response to "taking transit here is convenient" (binary) & 613 & 0.60 & 0.49 & 0 & 1 \\
\hline Car parking - negative & Negative response to "car parking here is easy \& convenient" (binary) & 648 & 0.22 & 0.42 & 0 & 1 \\
\hline Walking - negative & Negative response to "walking here is safe \& comfortable" (binary) & 673 & 0.09 & 0.29 & 0 & 1 \\
\hline Bicycling - negative & Negative response to "bicycling here is safe \& comfortable" (binary) & 616 & 0.17 & 0.38 & 0 & 1 \\
\hline Bike parking - negative & Negative response to "bike parking here is easy \& convenient" (binary) & 622 & 0.14 & 0.35 & 0 & 1 \\
\hline Transit - negative & Negative response to "taking transit here is convenient" (binary) & 613 & 0.19 & 0.39 & 0 & 1 \\
\hline
\end{tabular}


Table 3-7. Establishment Data Description

\begin{tabular}{|c|c|c|c|c|c|c|}
\hline Variable & Description & $\mathrm{N}$ & Mean & S.D. & Min & Max \\
\hline Walk mode share & & 78 & 0.250 & 0.189 & 0 & 0.750 \\
\hline Bike mode share & & 78 & 0.091 & 0.092 & 0 & 0.417 \\
\hline Automobile mode share & & 78 & 0.581 & 0.241 & 0.053 & 1.000 \\
\hline \multicolumn{7}{|c|}{ Aggregate socio-demographics } \\
\hline \% Phys. Limitation & $\%$ with physical limitation & 76 & 5.78 & 8.97 & 0 & 37.5 \\
\hline Avg income & Average income $(\$ 10,000 \mathrm{~s})$ & 76 & 7.23 & 2.89 & 1.75 & 18.75 \\
\hline Avg $\%$ male & Average $\%$ male & 76 & 56.60 & 21.71 & 0 & 100 \\
\hline Avg $\% 35+$ & Average $\%$ over age 35 & 76 & 48.71 & 20.21 & 0 & 100 \\
\hline$\% \mathrm{HH}$ with vehicle & $\%$ Households with at least one vehicle & 76 & 87.23 & 13.52 & 48 & 100 \\
\hline$\%$ HH with child & $\%$ Households with at least one child & 76 & 31.68 & 23.02 & 0 & 100 \\
\hline \multicolumn{7}{|c|}{ Aggregate trip characteristics } \\
\hline \% Home-based trips & $\%$ trips home-based & 76 & 81.23 & 18.72 & 29 & 100 \\
\hline$\%$ Work-based trips & $\%$ trips work-based & 76 & 23.35 & 19.41 & 0 & 100 \\
\hline Avg group size & Average group size & 76 & 1.65 & 0.47 & 1 & 3.2 \\
\hline Avg distance (mi) & Average trip distance (mi) & 76 & 3.22 & 2.00 & 0.17 & 9.5 \\
\hline \multicolumn{7}{|c|}{ Built environment characteristics } \\
\hline BE Factor & Built environment factor (from factor analysis) & 78 & 0.00 & 1.00 & -1.89 & 2.77 \\
\hline Low-stress bikeways & Lane-miles of low-stress bikeways within $0.5 \mathrm{mi}$ & 78 & 2.22 & 1.04 & 0 & 4.05 \\
\hline Highways & Lane-miles of state highways within $0.5 \mathrm{mi}$ & 78 & 0.63 & 0.79 & 0 & 2.82 \\
\hline On arterial & Site located on an arterial (binary) & 78 & 0.17 & 0.38 & 0 & 1 \\
\hline Shopping center & Site located in a shopping center (binary) & 78 & 0.21 & 0.41 & 0 & 1 \\
\hline Bike corral & Presence of a bike corral within 200ft of establishment (binary) & 78 & 0.14 & 0.35 & 0 & 1 \\
\hline Bike parking & Number of bicycle parking spots on site + on adjacent street / 10 & 78 & 0.82 & 1.69 & 0 & 10 \\
\hline
\end{tabular}




\subsection{Summary}

This chapter outlined the data collected at the restaurants, bars, and convenience stores, comprising 78 unique business locations in the Portland metro area.

The approach for bars, restaurants and convenience stores intercepted customers exiting the establishments from 5-7 p.m. on Mondays through Thursdays and gave respondents two survey options. The first was a "long" survey instrument administered by students using computer tablet technology and inquiring about demographics, origin and destinations, transportation choices, amount spent and frequency of visits. The second was a "short" survey instrument administered by students using a paper survey that asked respondents about their home location, mode of transportation, amount spend and frequency of visits.

These data are augmented by built-environment information at a half-mile buffer around each establishment. The data are pooled where possible for analysis of mode shares at the establishment level and mode choices at the individual level. The results of this analysis are included in the next chapter. 


\section{Chapter 4. Analysis Methods \& Results}

To assess the relationships between the built environment, personal and household characteristics, trip characteristics on travel mode choice at the individual level and mode share at the establishment level, we estimate three sets of models: one set for walk mode, one set for bicycle mode, and one set for automobile mode. Within each set, there are two models: a binary logistic regression models where the dependent variable is the probability of whether or not the individual will choose that travel mode, and an ordinary least squares (OLS) regression model where the dependent variable is the corresponding percent mode share at the establishment. ${ }^{11}$

We do not estimate models for transit mode because there were not enough observations of transit users at the establishment level to estimate a statistically acceptable OLS model for that mode. Accordingly, a transit mode choice model for individuals is not presented because comparisons between the two levels would not be possible. A single discrete mode choice model is not estimated for individual level data because several assumptions would have to have been made about the relative utility of each travel mode alternative at the time of the decision: assumptions about travel times and travel costs for this dataset probably would not be robust.

For each of the OLS models in this section, data for all establishments are pooled; convenience stores, restaurants, and bars are all evaluated together. Mode share models used data from both short and long surveys in estimation. The data for mode choice

\footnotetext{
${ }^{11}$ Models estimated with SPSS version 19
} 
models came from the long survey only, because socio-demographic information was not collected in the short survey.

This chapter presents regression analysis of individual mode choice and establishment mode share as outlined above.

\subsection{Walking Models}

Here a binary logistic regression model is estimated for the choice to walk of the individual along with an OLS model for the percent walk mode share of establishments (Table 4-1). Both control for store type, ${ }^{12}$ socio-demographic characteristics, trip characteristics, and built environment characteristics.

\subsubsection{Binary Logit Model - Choice to Walk}

The walk choice model highlights the factors associated with the choice to walk (-2LL = 425.18, Model $\left.\chi^{2}=278.64\right)$. The significant predictors of the choice to walk are store type, household vehicle availability, presence of children in the household, a work-based trip, a positive attitude toward waking, trip distance, and the built environment.

Physical limitations, household income, gender, age, presence of children in the household, a home-based trip, group size, and attitudes towards car parking at the destination are not significantly related to the choice to walk.

Convenience stores $(\mathrm{B}=0.69, \mathrm{OR}=2.00, \mathrm{p}<0.05)$ and bars $(\mathrm{B}=0.72, \mathrm{OR}=2.06, \mathrm{p}<$ 0.10) are associated with doubled odds of walking over restaurants.

\footnotetext{
${ }^{12}$ Restaurants are used as the base case.
} 
The model agrees with existing literature that shows vehicle availability is associated with lower levels of walking (Frank, Saelens, Powell, \& Chapman, 2007; Rajamani et al., 2003). If there is a vehicle present in the household, individuals are $76 \%$ less likely to walk than when there is no vehicle present $(B=-1.44, \mathrm{OR}=0.24, \mathrm{p}<0.001)$. A child in the home is associated with a greater chance of walking as well $(\mathrm{B}=0.55, \mathrm{OR}=1.73, \mathrm{p}<$ $0.10)$, but the result is marginally significant.

Individuals traveling to or from work are less likely to walk. If the trip origin or next destination is work, then the likelihood of walking is 0.36 times that if not $(\mathrm{B}=-1.03, \mathrm{OR}$ $=0.36, \mathrm{p}<0.01)$. Trip distance is also important. For each additional mile of the trip, the $\log$ odds of choosing to walk for that trip decrease by $0.95(B=-0.95$, OR $=0.39, p<$ 0.001). In other words, for every additional mile of the trip, the odds of choosing to walk are 0.39 that of one mile shorter.

An attitude in favor of walking is a large predictor of the choice to walk. Respondents who agreed or strongly agreed that walking was safe and comfortable near the destination were $329 \%$ more likely to walk $(B=1.46, \mathrm{OR}=4.29, \mathrm{p}<0.01)$. The model coefficients show that a positive attitude towards walking is the strongest predictor of choosing to walk, all else held constant.

The built environment at the trip destination has a strong effect on walking, as shown by the coefficient on the built environment factor in Table 4-1. For every unit increase in the built environment factor, the odds of walking increase by $60 \%(\mathrm{~B}=0.46, \mathrm{OR}=1.60, \mathrm{p}<$ 0.01). Also, if the establishment is located on an arterial, the choice to walk is reduced by $82 \%$ when all other variables are held constant $(B=-1.69, \mathrm{OR}=0.18, \mathrm{p}<0.01)$. 


\subsubsection{Linear Regression - Walk Mode Share}

The OLS regression model $\left(\mathrm{N}=76, \mathrm{Adj} . \mathrm{R}^{2}=0.60, \mathrm{SEE}=0.12\right)$ here uses the percent of customers arriving on foot as the dependent variable to explore the relationships between establishment-level characteristics and walking mode share.

Like the walking choice model, bars and convenience stores are binary variables included in the model to identify store type. Restaurants are used as the base case for this comparison. Convenience stores have a predicted $12.3 \%$ higher walking mode share than restaurants $(\mathrm{B}=0.123, \beta=0.31, \mathrm{p}<0.05)$, and drinking places do not have a statistically significant difference in walking mode share than restaurants $(B=0.071, \beta=0.14$, n.s. $)$.

With the exception of gender, none of the aggregated socio-demographic characteristics play a role in walking mode share. An increase in the average percent of male customers predicts a lower share of customers walking to the store $(\mathrm{B}=-0.002, \beta=-0.22, \mathrm{p}<0.05)$.

Of the aggregate trip characteristics, average trip distance is the only variable significantly associated with walking mode share. One additional mile in average trip length of patrons at the establishment predicts a $2.1 \%$ decrease in walking mode share (B $=-0.021, \beta=-0.23, \mathrm{p}<0.05)$.

The built environment factor has the biggest effect on walk mode share of any variable $(\mathrm{B}=0.140, \beta=0.76, \mathrm{p}<0.001)$. Low-stress bikeways also are significantly associated with more walking mode share. One added mile of these facilities near the establishment relates to a $3.9 \%$ increase in walk mode $(\mathrm{B}=0.039, \beta=0.22, \mathrm{p}<0.05)$. The variables representing whether the establishment is located on or near highways or in a shopping center are not significantly associated with a change in walking mode share. These results 
show that walking is more prominent in dense neighborhoods, and places with comfortable bicycling infrastructure (multi-use paths, low-traffic streets, low-speed streets with bike infrastructure, etc.) cater well to pedestrians.

\subsubsection{Comparisons between Models}

Between the individual walk mode choice model and the establishment walk mode share models, there are differences between significance in store type, gender, vehicles and children in the household, work-based trips, group size, and location on an arterial.

Bars are associated with a higher likelihood of walking in the individual model but the effect disappears in the aggregate walk mode share model.

Males are insignificantly associated with a lower probability of walking at the individual level, but this effect becomes significant in the aggregate model where one more percent increase in male patronage is related to a $0.2 \%$ reduction in walk mode. Vehicles and children in the household are associated with lower and higher likelihood of walking at the individual level and these effects disappear on the aggregate.

Of the trip characteristics important to the individual choice to walk-work-based trips, group size, and distance-every effect but distance becomes insignificant in the aggregate model. When examining standardized regression coefficients, ${ }^{13}$ the distance variable has by far the strongest relationship with walk mode choice, but its relationship is weaker than the built environment factor and the convenience store variable in the walk mode share model

\footnotetext{
${ }^{13}$ See Appendix E for an explanation of how standardized coefficients in logistic regression models were estimated.
} 
The built environment factor has the largest standardized association with predicted walk mode share at establishments. But at the individual choice level, the built environment factor's standardized effect ranked fifth among the nine significant independent variables.

Low-stress bikeways near the establishment are not significant in the choice model but then become important in the aggregate walking mode share model. Location on an arterial drops out of significance in the aggregate model and the coefficient even switches direction and becomes positive. The reason for the change in sign is unknown.

The only consistently significant variables between the two models are convenience store type, trip distance, and built environment factor. Convenience stores are clearly associated with higher levels of walking. Longer trip distances see less walking. More urban areas have more people choosing to walk and see higher levels of walking. 
Table 4-1. Walking Regression Models

\begin{tabular}{|c|c|c|c|c|c|c|c|c|}
\hline \multicolumn{5}{|c|}{ Individual walk mode choice binary logit model } & \multicolumn{4}{|c|}{ Establishment walk mode share OLS model } \\
\hline Independent variable & B & SE & OR & $\beta_{\text {est }}$ & Independent variable & $\mathrm{b}$ & $\mathrm{SE}_{\mathrm{b}}$ & $\beta$ \\
\hline Intercept & $1.191 * *$ & 0.831 & 3.291 & & Intercept & 0.253 & 0.173 & \\
\hline Establishment characteristics & & & & & Establishment characteristics & & & \\
\hline Conv. store (binary) & $0.691^{* *}$ & 0.332 & 1.995 & 0.053 & Conv. store (binary) & $0.123^{* *}$ & 0.050 & 0.313 \\
\hline Bar (binary) & $0.723 *$ & 0.377 & 2.060 & 0.041 & Bar (binary) & 0.071 & 0.045 & 0.144 \\
\hline Socio-demographics & & & & & Aggregate socio-demographics & & & \\
\hline Phys. limitation & -0.167 & 0.492 & 0.846 & -0.007 & $\%$ Phys. Limitation & 0.001 & 0.002 & 0.065 \\
\hline Income & -0.021 & 0.023 & 0.979 & -0.019 & Avg income & -0.004 & 0.006 & -0.059 \\
\hline Gender & -0.360 & 0.250 & 0.698 & -0.028 & Avg $\%$ male & $-0.002^{* *}$ & 0.001 & -0.218 \\
\hline Age $35+$ & 0.018 & 0.271 & 1.019 & 0.001 & Avg \% 35+ & 0.000 & 0.001 & -0.053 \\
\hline Vehicle in $\mathrm{HH}$ & $-1.443 * * * *$ & 0.367 & 0.236 & -0.080 & $\% \mathrm{HH}$ with vehicle & 0.001 & 0.001 & 0.105 \\
\hline Child in $\mathrm{HH}$ & $0.546^{*}$ & 0.322 & 1.727 & 0.038 & $\%$ HH with child & 0.001 & 0.001 & 0.167 \\
\hline Trip characteristics & & & & & Aggregate trip characteristics & & & \\
\hline Home-based trip & -0.171 & 0.352 & 0.842 & -0.010 & $\%$ Home-based trips & -0.001 & 0.001 & -0.053 \\
\hline Work-based trip & $-1.027 * * *$ & 0.350 & 0.358 & -0.068 & $\%$ Work-based trips & 0.000 & 0.001 & 0.039 \\
\hline Group size & $-0.258 *$ & 0.152 & 0.772 & -0.037 & Avg group size & -0.031 & 0.043 & -0.079 \\
\hline Distance & $-0.947 * * * *$ & 0.137 & 0.388 & -0.584 & Avg distance (mi) & $-0.021^{* *}$ & 0.009 & -0.226 \\
\hline \multicolumn{9}{|l|}{ Attitudes } \\
\hline Car parking - positive & -0.229 & 0.273 & 0.795 & -0.018 & & & & \\
\hline Walking - positive & $1.456 * * *$ & 0.445 & 4.289 & 0.092 & & & & \\
\hline
\end{tabular}




\begin{tabular}{|c|c|c|c|c|c|c|c|c|}
\hline \multicolumn{5}{|c|}{ Individual walk mode choice binary logit model } & \multicolumn{4}{|c|}{ Establishment walk mode share OLS model } \\
\hline Independent variable & $\mathrm{B}$ & SE & OR & $\beta_{\text {est }}$ & Independent variable & $\mathrm{b}$ & $\mathrm{SE}_{\mathrm{b}}$ & $\beta$ \\
\hline Built environment characteristics & & & & & Built environment characteristics & & & \\
\hline BE Factor & $0.455 * * *$ & 0.156 & 1.577 & 0.069 & BE Factor & $0.140 * * * *$ & 0.019 & 0.762 \\
\hline Low-stress bikeways & 0.033 & 0.137 & 1.034 & 0.006 & Low-stress bikeways & $0.039 * *$ & 0.015 & 0.219 \\
\hline Highways & -0.300 & 0.205 & 0.741 & -0.038 & Highways & -0.031 & 0.022 & -0.129 \\
\hline On arterial & $-1.693 * * *$ & 0.498 & 0.184 & -0.090 & On arterial & 0.014 & 0.049 & 0.029 \\
\hline Shopping center & 0.184 & 0.459 & 1.202 & 0.011 & Shopping center & 0.004 & 0.042 & 0.008 \\
\hline Overall model statistics & & $\mathrm{df}$ & & & Overall model statistics & & & \\
\hline $\mathrm{N}$ & 594 & & & & $\mathrm{~N}$ & 76 & & \\
\hline-2 Log-likelihood & 425.18 & & & & $R^{2}$ & 0.69 & & \\
\hline Model Chi-square & $278.64 * * * *$ & 19 & & & Adjusted $R^{2}$ & 0.60 & & \\
\hline Cox \& Snell R square & 0.37 & & & & Standard error of the estimate & 0.12 & & \\
\hline Nagelkerke R square & 0.54 & 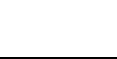 & & & & & & \\
\hline
\end{tabular}

*significant at $\mathrm{p}<0.10 ; * *$ significant at $\mathrm{p}<0.05 ; * * *$ significant at $\mathrm{p}<0.01 ; * * * *$ significant at $\mathrm{p}<0.001$ 


\subsection{Bicycling Models}

Here a binary logistic regression is estimated for the individual choice to ride a bicycle along with an OLS regression to estimate the percent bike mode share at the establishment. The estimations are similar to the walking models, but bike parking characteristics are used in the built environment variables instead of highway and arterial attributes to better reflect the bicycling environment. Table 4-2 shows model results.

\subsubsection{Binary Logit Model - Choice to Ride Bicycle}

This model details the factors associated with bicycling mode choice $(-2 \mathrm{LL}=300.38$, Model $\chi^{2}=70.22$ ). The significant predictors of the choice to ride a bicycle are a trip to a bar, household income, gender, age, a work-based trip, attitudes towards car parking at the destination, and attitudes towards bicycling at the destination. Physical limitations, car ownership, children in the household, group size, attitudes about bicycle parking, and the built environment do not significantly affect the choice of whether to ride a bicycle.

Like the walk models, store type is significantly related to mode choice. Mode choice is more likely to be bicycle when travelling to drinking places $(\mathrm{B}=1.06, \mathrm{OR}=2.87, \mathrm{p}<$ 0.05). Bars alone are the largest predictor in magnitude of log odds a choosing to ride a bicycle in the model. But, this variable's standardized coefficient estimate ranks fourth among the seven significant variables.

Higher household income is related to having lower odds of choosing to ride a bicycle. The model shows that for every additional $\$ 10,000$ in income, the log odds of choosing to ride a bicycle decrease by $0.09(\mathrm{~B}=-0.09, \mathrm{OR}=0.91, \mathrm{p}<0.05)$. The standardized effect of income is the largest of all significant variables $(\beta=-0.17)$. Gender is a large 
determinant in the choice to ride a bicycle. Males are almost twice as likely as females to use bicycles for travel in the model, but the result has marginal significance $(B=0.66$, $\mathrm{OR}=1.93, \mathrm{p}<0.10)$. Also significant is age. An age over 35 predicts a $48 \%$ lower odds of riding a bicycle, all other variables held constant $(\mathrm{B}=-0.66, \mathrm{OR}=0.52, \mathrm{p}<0.10)$.

Work-based trips are associated with increased odds of riding a bicycle. If the trip to the establishment comes from work or if the destination after the establishment is work, travelers are $175 \%$ more likely to ride a bicycle than other modes $(B=1.01, O R=2.75, p$ $<0.01)$.

Attitudes about transportation at the destination are important in the choice to ride a bicycle. If the traveler thinks there is easy car parking at the destination, then the odds of choosing to ride a bicycle are 0.53 that of a traveler who thinks otherwise $(B=-0.64$, OR $=0.53, \mathrm{p}<0.05)$. A positive attitude towards bicycling in the neighborhood of the destination is also significantly related to choosing to ride a bike there: travelers who feel this way are 2.2 times as likely to ride a bike than those who feel otherwise $(B=0.77$, $\mathrm{OR}=2.16, \mathrm{p}<0.05)$. Attitudes towards bicycling have the second largest effect of any variable in the model, but attitudes in favor of bike parking do not significantly affect mode choice.

It is of particular interest that the built environment factor, low-stress bikeways, and bike parking do not affect the choice to ride a bicycle. One thesis is that the built environment factors might not influence the choice to ride as much as the choice to walk because bicycles move through the environment at a faster rate than people on foot. Alternatively, 
the data here represent the built environment at the destination end, and the influence of the environment on the choice could be stronger at other points of the trip.

\subsubsection{Linear Regression - Bike Mode Share}

The OLS regression model $\left(N=76\right.$, Adj. $\left.R^{2}=0.60, S E E=0.12\right)$ here uses the percent of customers arriving on bicycles as the dependent variable to explore the relationships between establishment-level characteristics and bike mode share.

The store type variables are included in the same manner as the walking mode share model, where restaurants are the base case. Bars are associated with bicycle mode shares significantly greater than those of restaurants and convenience markets. The characteristic of a business being a bar on its own is significantly associated with a bicycle mode share $8.7 \%$ higher than the other types of businesses included in the study $(\mathrm{B}=0.087, \beta=0.36, \mathrm{p}<0.01)$.

The only other significant predictors of mode share are variables representing bicycle parking provision. If the establishment has a bike corral within 200 feet of the building, the model estimates an $8.3 \%$ increase in bike mode share $(\mathrm{B}=0.083, \beta=0.32$, $\mathrm{p}<0.01)$. Bicycle parking (calculated as the number of bicycle parking spaces on-site and on the adjacent street, excluding those in bike corrals) is also a significant independent predictor of bicycling mode share. Every 10 bicycle parking spaces provided is related to a $1.5 \%$ increase in bike mode share $(\mathrm{B}=0.015, \beta=0.29, \mathrm{p}<0.01)$. None of the aggregate sociodemographics or trip characteristics are significant. 


\subsubsection{Comparisons between Models}

Drinking places are consistent across both models. The choice to ride is increased when the trip is to a bar, and from the establishment end it is clear that bars see more bicyclists comprising the observed customer base.

None of the socio-demographics related to the choice to travel by bike (income, gender and age) maintain significance as predictors of mode share when aggregated to the establishment level. Work-based trips also lose significance between individual and establishment models.

Interestingly, trip distance and the built environment are not significant in either model. The coefficients for trip distance are both negative, however, indicating that longer distances may be a deterrent to bicycling. The coefficients for the built environment factor are both positive, but the coefficients for low-stress bikeways change direction across models. In the choice model the low-stress bikeway coefficient is positive but in the mode share model is small but negative.

The largest mismatch between the individual bike mode choice and aggregate bike mode share models is about bike parking. In the choice model, individual attitude towards bike parking, a bike corral, and bike parking are insignificant. In the mode share model, bike corrals $(\mathrm{B}=0.083, \beta=0.32, \mathrm{p}<0.01)$ and bike parking $(\mathrm{B}=0.015, \beta=0.29, \mathrm{p}<0.01)$ are both large and significant. It is unclear why such a mismatch exists. 
Table 4-2. Bicycling Regression Models

\begin{tabular}{|c|c|c|c|c|c|c|c|c|}
\hline \multicolumn{5}{|c|}{ Individual bike mode choice binary logit model } & \multicolumn{4}{|c|}{ Establishment bike mode share OLS model } \\
\hline Independent variable & B & SE & OR & $\beta_{\text {est }}$ & Independent variable & $\mathrm{b}$ & SE & $\beta$ \\
\hline Intercept & $-2.190 * * *$ & 0.917 & 0.112 & & Intercept & 0.097 & 0.099 & \\
\hline Establishment characteristics & & & & & Establishment characteristics & & & \\
\hline Conv. store (binary) & -0.191 & 0.408 & 0.826 & -0.029 & Conv. store (binary) & -0.002 & 0.027 & -0.012 \\
\hline Bar (binary) & $1.055 * *$ & 0.417 & 2.873 & 0.117 & Bar (binary) & $0.087^{* * *}$ & 0.025 & 0.358 \\
\hline Socio-demographics & & & & & Aggregate socio-demographics & & & \\
\hline Phys. limitation & -0.214 & 0.800 & 0.807 & -0.017 & $\%$ Phys. Limitation & 0.000 & 0.001 & 0.000 \\
\hline Income & $-0.093 * *$ & 0.040 & 0.912 & -0.168 & Avg income & -0.004 & 0.004 & -0.124 \\
\hline Gender & $0.661 *$ & 0.346 & 1.936 & 0.100 & Avg $\%$ male & 0.000 & 0.000 & 0.011 \\
\hline Age $35+$ & $-0.655^{*}$ & 0.365 & 0.519 & -0.100 & Avg \% 35+ & 0.000 & 0.000 & -0.081 \\
\hline Vehicle in $\mathrm{HH}$ & -0.120 & 0.416 & 0.887 & -0.013 & $\%$ HH with vehicle & 0.000 & 0.001 & -0.060 \\
\hline Child in $\mathrm{HH}$ & 0.249 & 0.415 & 1.283 & 0.034 & $\%$ HH with child & 0.000 & 0.001 & 0.059 \\
\hline Trip characteristics & & & & & Aggregate trip characteristics & & & \\
\hline Home-based trip & -0.180 & 0.419 & 0.835 & -0.021 & $\%$ Home-based trips & 0.000 & 0.000 & 0.066 \\
\hline Work-based trip & $1.011 * * *$ & 0.345 & 2.748 & 0.131 & $\%$ Work-based trips & 0.000 & 0.000 & 0.093 \\
\hline Group size & -0.239 & 0.209 & 0.788 & -0.067 & Avg group size & 0.005 & 0.025 & 0.026 \\
\hline Distance & -0.087 & 0.056 & 0.917 & 0.105 & Avg distance (mi) & -0.003 & 0.005 & -0.057 \\
\hline \multicolumn{9}{|l|}{ Attitudes } \\
\hline Car parking - positive & $-0.644 * *$ & 0.339 & 0.525 & -0.098 & & & & \\
\hline Bicycling - positive & $0.768 * *$ & 0.376 & 2.156 & 0.117 & & & & \\
\hline Bike parking - positive & -0.091 & 0.396 & 0.913 & -0.013 & & & & \\
\hline
\end{tabular}




\begin{tabular}{|c|c|c|c|c|c|c|c|c|}
\hline \multicolumn{5}{|c|}{ Individual bike mode choice binary logit model } & \multicolumn{4}{|c|}{ Establishment bike mode share OLS model } \\
\hline Independent variable & B & SE & OR & $\beta_{\text {est }}$ & Independent variable & $\mathrm{b}$ & SE & $\beta$ \\
\hline \multicolumn{5}{|c|}{ Built environment characteristics } & \multicolumn{4}{|l|}{ Built environment characteristics } \\
\hline BE Factor & 0.128 & 0.197 & 1.137 & 0.038 & BE Factor & 0.008 & 0.010 & 0.085 \\
\hline Low-stress bikeways & 0.177 & 0.154 & 1.194 & 0.067 & Low-stress bikeways & -0.004 & 0.008 & -0.045 \\
\hline Bike corral & -0.012 & 0.084 & 0.988 & -0.007 & Bike corral & $0.083^{* * *}$ & 0.024 & 0.319 \\
\hline Bike parking & 0.054 & 0.064 & 1.056 & 0.031 & Bike parking & $0.015^{* * *}$ & 0.005 & 0.287 \\
\hline \multicolumn{2}{|l|}{ Overall model statistics } & \multicolumn{3}{|l|}{$\mathrm{df}$} & \multicolumn{4}{|l|}{ Overall model statistics } \\
\hline $\mathrm{N}$ & \multicolumn{4}{|l|}{550} & $\mathrm{~N}$ & \multicolumn{3}{|l|}{76} \\
\hline -2 Log-likelihood & \multicolumn{4}{|l|}{300.38} & $R^{2}$ & \multicolumn{3}{|l|}{0.69} \\
\hline Model Chi-square & $70.22 * * * *$ & \multicolumn{3}{|l|}{19} & Adjusted $R^{2}$ & \multicolumn{3}{|l|}{0.60} \\
\hline Cox \& Snell R square & \multicolumn{4}{|l|}{0.12} & Standard error of the estimate & \multicolumn{3}{|l|}{0.12} \\
\hline Nagelkerke R square & \multicolumn{4}{|l|}{0.24} & & & & \\
\hline
\end{tabular}




\subsection{Automobile Models}

Here a binary logistic regression is estimated for the individual choice to drive or ride in an automobile along with an OLS regression to estimate the percent automobile mode share at the establishment.

\subsubsection{Binary Logit - Automobile Mode Choice}

This model examines the factors associated with vehicle mode choice $(-2 \mathrm{LL}=489.70$, Model $\left.\chi^{2}=224.85\right)$. The dependent variable is whether the trip to the site used an automobile-drivers and passengers are combined in the analysis. The significant predictors of automobile mode choice are establishment type, age, vehicle availability, presence of children, group size, trip distance, attitudes about parking, and characteristics of the built environment at the destination.

When other factors are held constant, people are more likely to make a vehicle trip to restaurants than they are at convenience stores $(\mathrm{B}=-0.88, \mathrm{OR}=0.41, \mathrm{p}<0.01)$ and bars $(\mathrm{B}=-1.03, \mathrm{OR}=0.36, \mathrm{p}<0.01)$.

Older people are more likely to drive or ride in vehicles. An age of 35 or older is associated with a $95 \%$ greater odds of traveling in a vehicle over younger people $(\mathrm{B}=$ $0.67, \mathrm{OR}=1.95, \mathrm{p}<0.05)$. The presence of at least one vehicle in the household is the largest independent predictor of driving or riding in an automobile. If the household has at least one vehicle, the odds of driving or riding as a passenger are almost 17 times that of a zero-car household $(\mathrm{B}=2.83, \mathrm{OR}=16.89, \mathrm{p}<0.001)$. The presence of children in the household is related to a lower probability of traveling via automobile. Presence of at 
least one child at home reduces the log odds of driving or riding in a vehicle by 0.66 (B = $-0.66, \mathrm{OR}=0.52, \mathrm{p}<0.05)$.

Bigger groups increase the predicted probability of traveling by vehicle. Each additional person in the group raises the odds of traveling via automobile by $26 \%(\mathrm{~B}=0.23, \mathrm{OR}=$ $1.26, \mathrm{p}<0.10$ ). Longer trip distances are associated with a higher probability of using an automobile. Each additional mile of the trip increases the log odds of using a vehicle by $0.16(\mathrm{~B}=0.16, \mathrm{OR}=1.17, \mathrm{p}<0.001)$.

An attitude in agreement with car parking at the establishment being easy and convenient is a large predictor of the choice to drive or ride as a passenger in a vehicle. People who feel this way have $123 \%$ higher odds to use a vehicle than those who do not $(B=0.80$, $\mathrm{OR}=2.23, \mathrm{p}<0.01)$. Interestingly, the choice to use a vehicle is not significantly impacted by negative attitudes towards walking, bicycling, bike parking, or transit: none of those controls are significant in the model.

The built environment has a strong impact on the probability of traveling by vehicle. Every unit increase in the built environment factor lowers the odds of choosing automobile by $44 \%(\mathrm{~B}=-0.57, \mathrm{OR}=0.56, \mathrm{p}<0.01)$. More low-stress bikeways at the establishment are associated with a higher odds of choosing automobile in the model (B $=0.15, \mathrm{OR}=1.17, \mathrm{p}<0.10)$. It is surprising these facilities relate to automobile mode choice in this manner, the opposite is expected. The result is marginally significant, however. Sites located on arterials $(\mathrm{B}=1.33, \mathrm{OR}=3.77, \mathrm{p}<0.01)$ or in shopping centers $(\mathrm{B}=0.53, \mathrm{OR}=1.69, \mathrm{p}<0.01)$ are both associated with higher probabilities of driving or riding as a passenger in a car. 


\subsubsection{Linear Regression - Automobile Mode Share}

The OLS regression model $\left(\mathrm{N}=76, \mathrm{Adj} . \mathrm{R}^{2}=0.78, \mathrm{SEE}=0.13\right)$ here uses the percent of customers arriving by vehicle as the dependent variable to explore the relationships between establishment-level characteristics and bike mode share.

Controlling for the type of business shows that drinking places have a different level of automobile mode share than the other land uses in study. Bars have a $12.7 \%$ lower automobile mode share than other establishment types $(\mathrm{B}=-0.127, \beta=-0.20, \mathrm{p}<0.05)$. This result is perhaps a relief to the Oregon Liquor Control Commission.

The only aggregate socio-demographic characteristic significantly associated with automobile mode share is percent of households with a child, which was marginally significant. For each additional percent of the customer base with children, predicted vehicle mode share decreases $0.2 \%(\mathrm{~B}=-0.002, \beta=-0.18, \mathrm{p}<0.10)$.

The aggregate trip characteristics significant in predicting automobile mode share are work-based trips and distance. Vehicle mode share decreases as more customer trips are work-based $(\mathrm{B}=-0.002, \beta=-0.17, \mathrm{p}<0.05)$. As average trip distance of customers increases, predicted automobile mode share increases as well $(\mathrm{B}=0.021, \beta=0.18, \mathrm{p}<$ $0.05)$.

The model shows that the built environment has the biggest overall impact on vehicle mode share. A unit change in the built environment factor predicts $16.1 \%$ fewer patrons arriving by vehicle $(\mathrm{B}=-0.162, \beta=-0.67, \mathrm{p}<0.001)$. More low-stress bikeways near the establishment are associated with lower vehicle mode share as well $(\mathrm{B}=-0.028, \beta=-$ $0.12, \mathrm{p}<0.10)$. Establishments located in shopping centers are estimated to have $8 \%$ 
higher automobile mode shares than those that are not, all other variables held constant $(\mathrm{B}=0.080, \beta=0.14, \mathrm{p}<0.10)$.

\subsubsection{Comparisons between Models}

Between the disaggregate choice and aggregate mode share models for the automobile, differences exist in store type, socio-demographics, trip characteristics, and the built environment.

The convenience store variable drops significance between the choice model and the mode share model. Trips to convenience stores and bars have lower odds of being performed with an automobile than restaurants at the individual level, but at the aggregate level only bars see automobile mode shares lower than restaurants.

None of the socio-demographics significant at the individual level-age, vehicle availability, children-except households with children maintain an effect on the aggregate. It is surprising that vehicle availability, by far the largest predictor of the probability of traveling by vehicle in the individual level model, does not have a significant impact on mode shares. The regression coefficients of the aggregate sociodemographic variables are all very small, despite their magnitude in the individual choice model. This "weakening", however, may be due to the construction of the aggregate variables.

The trip characteristics with differences are work-based trips and group size. Work-based trips become a significant predictor in the aggregate model but are not relevant in the individual model. Larger groups are related to automobile choice, but they are not significant in the automobile mode share estimation. Establishments that attract larger 
groups on average would be expected to generate more vehicle mode share if the groups were carpooling together.

The built environment characteristics inconsistent between the automobile models are low-stress bikeways and whether the site is located on an arterial. The coefficients on the variable for low-stress bikeways are both significant but in different directions. A positive association exists in the choice model between low-stress bikeways and automobile choice, but a negative relationship is present between the variable and vehicle mode share. A negative relationship at both levels is expected, and it is unclear why the positive relationship exists at the individual level. The variable for site location on an arterial is a significant attractor to vehicle mode choice but is not significantly related to vehicle mode share.

The consistent variables between the two models are the dummy variable for bars, households with children, trip distance, the built environment factor, and whether the site is in a shopping center.

Bars see lower vehicle mode shares, and individuals are less likely to travel by vehicle to them when all other variables are held constant. This effect is not easily explained by any other trends in the dataset: it could be due to a social norm, but there is no evidence here to confirm this idea.

Households with children are less likely to travel by vehicle, and as the amount of customers at the establishment with children increases, the vehicle mode share decreases. This consistent effect is surprising. Normally, one would expect that parents traveling with kids would be driving them in a vehicle. But, the variables here represent only 
whether there is a child in the home, so it does not mean that they were part of the trip when data collection occurred.

Trip distance is significant at both levels, as expected. Longer trips mean more likelihood of vehicle travel, and longer trips on average equate to higher automobile mode shares. From this result alone, policies to reduce trip lengths like containing the urban environment through a growth boundary or mixing land uses to bring housing and workplaces closer together may be effective at reducing emissions from vehicle travel.

The built environment is consistent across both levels of behavior. Establishments in more urban areas see lower rates of vehicle mode choice and lower vehicle mode shares. On the aggregate, the built environment becomes the largest independent predictor of automobile mode share. Also, sites in shopping centers, where sites are oriented towards car parking and car circulation, see more vehicle mode share and more people choosing to travel via automobile than sites located independently. Together, these results indicate that the built environment surrounding the site and the accommodation towards vehicles at the site play an important role in travel behavior. 
Table 4-3. Automobile Regression Models

\begin{tabular}{|c|c|c|c|c|c|c|c|c|}
\hline \multicolumn{5}{|c|}{ Individual automobile mode choice binary logit model } & \multicolumn{4}{|c|}{ Establishment automobile mode share OLS model } \\
\hline Independent variable & $\mathrm{B}$ & SE & OR & $\beta_{\mathrm{est}}$ & Independent variable & $\mathrm{b}$ & $\mathrm{SE}_{\mathrm{b}}$ & $\beta$ \\
\hline Intercept & $-4.233 * * * *$ & 0.879 & 0.015 & & Intercept & $0.428^{* *}$ & 0.190 & \\
\hline Establishment characteristics & & & & & Establishment characteristics & & & \\
\hline Conv. store (binary) & $-0.882^{* * *}$ & 0.307 & 0.414 & -0.132 & Conv. store (binary) & -0.040 & 0.055 & -0.078 \\
\hline Bar (binary) & $-1.029^{* * *}$ & 0.348 & 0.357 & -0.114 & Bar (binary) & $-0.127^{* *}$ & 0.049 & -0.199 \\
\hline Socio-demographics & & & & & Aggregate socio-demographics & & & \\
\hline Phys. limitation & 0.466 & 0.482 & 1.593 & 0.036 & \% Phys. Limitation & 0.000 & 0.002 & 0.011 \\
\hline Income & 0.035 & 0.022 & 1.036 & 0.063 & Avg income & 0.007 & 0.007 & 0.079 \\
\hline Gender & -0.097 & 0.239 & 0.907 & -0.015 & Avg $\%$ male & 0.001 & 0.001 & 0.069 \\
\hline Age $35+$ & $0.666 * *$ & 0.241 & 1.946 & 0.102 & Avg \% 35+ & 0.001 & 0.001 & 0.100 \\
\hline Vehicle in $\mathrm{HH}$ & $2.827 * * * *$ & 0.565 & 16.893 & 0.308 & $\% \mathrm{HH}$ with vehicle & 0.001 & 0.001 & 0.034 \\
\hline Child in $\mathrm{HH}$ & $-0.658 * *$ & 0.278 & 0.518 & -0.090 & $\%$ HH with child & $-0.002^{*}$ & 0.001 & -0.182 \\
\hline Trip characteristics & & & & & Aggregate trip characteristics & & & \\
\hline Home-based trip & -0.007 & 0.341 & 0.993 & -0.001 & $\%$ Home-based trips & -0.001 & 0.001 & -0.042 \\
\hline Work-based trip & -0.052 & 0.290 & 0.949 & -0.007 & $\%$ Work-based trips & $-0.002^{* *}$ & 0.001 & -0.172 \\
\hline Group size & $0.231^{*}$ & 0.141 & 1.260 & 0.064 & Avg group size & 0.078 & 0.047 & 0.152 \\
\hline Distance & $0.159 * * * *$ & 0.039 & 1.173 & 0.192 & Avg distance (mi) & $0.021^{* *}$ & 0.010 & 0.176 \\
\hline \multicolumn{9}{|l|}{ Attitudes } \\
\hline Car parking - positive & $0.801 * * *$ & 0.244 & 2.227 & 0.122 & & & & \\
\hline Walking - negative & 0.618 & 0.472 & 1.855 & 0.055 & & & & \\
\hline Bicycling - negative & 0.317 & 0.363 & 1.373 & 0.036 & & & & \\
\hline Bike parking - negative & -0.530 & 0.380 & 0.589 & -0.057 & & & & \\
\hline Transit - negative & 0.416 & 0.302 & 1.515 & 0.050 & & & & \\
\hline
\end{tabular}




\begin{tabular}{|c|c|c|c|c|c|c|c|c|}
\hline \multicolumn{5}{|c|}{ Individual automobile mode choice binary logit model } & \multicolumn{4}{|c|}{ Establishment automobile mode share OLS model } \\
\hline Independent variable & B & SE & OR & $\beta_{\text {est }}$ & Independent variable & $\mathrm{b}$ & $\mathrm{SE}_{\mathrm{b}}$ & $\beta$ \\
\hline \multicolumn{5}{|c|}{ Built environment characteristics } & \multicolumn{4}{|l|}{ Built environment characteristics } \\
\hline BE Factor & $-0.574 * * *$ & 0.154 & 0.563 & -0.171 & BE Factor & $-0.161 * * * *$ & 0.024 & -0.670 \\
\hline Low-stress bikeways & $0.153^{*}$ & 0.126 & 1.165 & 0.058 & Low-stress bikeways & $-0.028^{*}$ & 0.016 & -0.121 \\
\hline Highways & -0.101 & 0.185 & 0.904 & -0.025 & Highways & -0.027 & 0.024 & -0.086 \\
\hline On arterial & $1.327 * * *$ & 0.409 & 3.768 & 0.137 & On arterial & 0.034 & 0.053 & 0.053 \\
\hline Shopping center & $0.525 * * *$ & 0.400 & 1.690 & 0.059 & Shopping center & $0.080^{*}$ & 0.047 & 0.137 \\
\hline Overall model statistics & & \multicolumn{3}{|l|}{ df } & \multicolumn{4}{|l|}{ Overall model statistics } \\
\hline $\mathrm{N}$ & \multicolumn{4}{|l|}{516} & $\mathrm{~N}$ & \multicolumn{3}{|l|}{76} \\
\hline -2 Log-likelihood & \multicolumn{4}{|l|}{489.70} & $R^{2}$ & \multicolumn{3}{|l|}{0.78} \\
\hline Model Chi-square & \multicolumn{4}{|l|}{$224.85^{* * * * *}$} & Adjusted $R^{2}$ & \multicolumn{3}{|l|}{0.71} \\
\hline Cox \& Snell R square & \multicolumn{4}{|l|}{0.35} & Standard error of the estimate & \multicolumn{3}{|l|}{0.13} \\
\hline Nagelkerke R square & \multicolumn{4}{|l|}{0.47} & & & & \\
\hline
\end{tabular}




\subsection{Summary}

This chapter describes the analysis of mode choices of customers and mode shares at convenience stores, bars, and restaurants in a variety of built environment and transportation contexts. The automobile is the dominant mode of travel, but large proportions of customers arrive by non-automobile travel modes.

Regression analyses at the individual and the establishment levels highlight the important factors related to travel in the micro and macro environment. Table 4-4 summarizes results of binary logit mode choice models and Table 4-5 summarizes results from OLS mode share models. Both tables indicate the significant associations as well as the direction of the influence on the dependent variable.

Table 4-4. Summary of Binary Mode Choice Models

\begin{tabular}{llccc}
\hline & Variables & Walk & Bike & Automobile \\
\hline Establishment & Convenience store & + & & - \\
characteristics & Bar & + & + & - \\
\hline Socio-demographics & Income & & - & \\
& Gender $=$ M & & + & + \\
& Age $>35$ & & - & + \\
& Vehicle in HH & - & & - \\
& Child in HH & + & & + \\
\hline Trip characteristics & Work-based & - & + & + \\
& Group size & - & & + \\
& Distance & - & & - \\
\hline Attitudes & Positive towards car parking & & - & + \\
& Positive towards mode & + & + & + \\
\hline $\begin{array}{l}\text { Built environment } \\
\text { characteristics }\end{array}$ & BE Factor & + & & + \\
& Low-stress bikeways & & & + \\
& On arterial & - & & \\
& Shopping center & & & + \\
\hline
\end{tabular}

Note: only significant variables shown 
Table 4-5. Summary of OLS Mode Share Models

\begin{tabular}{|c|c|c|c|c|}
\hline \multicolumn{2}{|c|}{ Variables } & \multirow{2}{*}{$\begin{array}{c}\text { Walk } \\
+\end{array}$} & \multirow[t]{2}{*}{ Bike } & \multirow[t]{2}{*}{ Automobile } \\
\hline Establishment characteristics & Convenience store & & & \\
\hline & Bar & & + & - \\
\hline \multirow[t]{2}{*}{ Socio-demographic averages } & Avg. \% Male & - & & \\
\hline & $\%$ with Child in $\mathrm{HH}$ & & & - \\
\hline \multirow[t]{3}{*}{ Trip characteristic averages } & $\%$ Work-based & & & - \\
\hline & Avg. group size & & & \\
\hline & Avg. distance & - & & + \\
\hline \multirow{6}{*}{$\begin{array}{l}\text { Built environment } \\
\text { characteristics }\end{array}$} & BE Factor & + & & - \\
\hline & Low-stress bikeways & + & & - \\
\hline & On arterial & & & \\
\hline & Shopping center & & & + \\
\hline & Bike corral & & + & \\
\hline & Bike parking & & + & \\
\hline
\end{tabular}

Note: only significant variables shown

Binary mode choice models show that aspects of socio-demographics, trip characteristics, attitudes, and the built environment affect mode choices when controlling for store type. Mode share models show that the same factors affect behavior observed at the site level. But, when individual socio-demographics and trip characteristics are aggregated to the site level, they seem to matter less than store type controls and the built environment.

It is not evident what causes the differences between the two levels. Ortuzár and Willumsen note that with aggregation, the inherent variability within the disaggregate data is lost (2001, p. 221). Some of the average values used at the establishment level could have low reliability due to sample sizes (Snijders \& Bosker, 2011, p. 14), as in some cases the number of long surveys collected at one site was small. Also, the establishment mode share estimation used observations from the disaggregate longsurvey dataset as well as observations from the short-survey dataset. 
We suspect that the characteristics that are significant at both levels-for walking: store type, trip distance, built environment; for bicycling: store type; for automobile: store type, children in the household, trip distance, built environment, and location in shopping center-have the strongest relationships with travel for the modes in study.

Results of the models examined across the three travel modes shows that walking and vehicle modes have similar characteristics but in opposite directions and that bicycling behaves quite differently. The built environment factor is the largest single predictor of mode share for both walk and automobile modes at the establishment level. The magnitudes of the coefficients are $\mathrm{B}_{\text {walk }}=0.14$ and $\mathrm{B}_{\text {automobile }}=-0.16$, corresponding to $\mathrm{a}$ $14 \%$ increase and $16 \%$ decrease in walk and automobile mode share given a one unit increase in the built environment factor. However, in both the bicycle mode choice and bicycle mode share models, the built environment factor is not a significant predictor of the outcome variable. The sizes of the estimated coefficients on the built environment factor variable are much smaller than for the other two modes. For example, the estimate of the built environment factor coefficient in the mode share model is $\mathrm{B}_{\text {bicycle }}=0.008$, which is much smaller than the corresponding estimate in the walk mode share model.

Similarly, trip distance matters for walk and automobile modes, but not for bicycling. Travelers on foot have inherently less range during a given duration of travel than bicyclists and drivers/passengers, and in the models distance is a significant negative predictor of walking at both analysis levels. Those traveling in vehicles have the most range, as cars have the highest travel speeds of all modes in the study. The automobile 
models show that longer distances are associated with more automobile travel. In the bicycling models, however, distance is not significant. 


\section{Chapter 5. Conclusions}

This thesis utilizes establishment-based data from a trip generation study to examine the mode choice for non-work travel at the level of the individual traveler and the mode share at the level of the establishment. It is unique in that the body of literature has typically studied travel behavior using residential-based transportation data. By analyzing data as mode shares at individual establishments and mode choices of individual customers, the study identifies characteristics of the built environment and the individual traveler that are relevant to planning policies aimed at supporting non-automobile travel. This chapter discusses these key findings of the research in more depth, in addition to implications for policy, limitations, and future work.

\subsection{Key Findings}

Here we address the research questions from Chapter 1.

\section{What are the relationships between the built environment and mode choices?}

There are strong relationships between the built environment and walk mode choice. The built environment factor ${ }^{14}$ has a large impact on walking choice. Destinations with higher levels of activity density, intersection density, lot coverage, housing type mix, and short distances to rail increase the odds of customers choosing to travel on foot to them. Additionally, if a site is located on an arterial street, customers are much less likely to choose walking as their travel mode to get there, all else held constant.

\footnotetext{
${ }^{14}$ See $\$ 3.3$ for a detailed explanation of the built environment factor and its underlying attributes. In short, it is a measure developed from individual attributes that describes the overall urban character of each study site.
} 
Interestingly, this analysis did not find any significant independent relationships between the built environment attributes studied and bicycle mode choice when controlling for attitudes towards bicycling, trip characteristics, and socio-demographics.

We find three key relationships between the built environment and automobile mode choice. First, the built environment factor has a negative relationship with automobile mode choice, suggesting as expected that individuals are more to choose non-automobile modes in urban sites. Second, site location on an arterial has a strong relationship with the choice to either drive or carpool, which is logical because arterials carry large volumes of vehicles. Third, automobile mode choice is more likely when the site is located in a car-oriented shopping center.

\section{How do these relationships differ between travel modes?}

The built environment and mode choice relationships are quite different between travel modes. Findings show that walking mode choice is more likely in increasingly urban areas and when destinations are not located on arterials. Automobile choice is opposite: choosing to drive or carpool is less likely to occur in urban areas and is more likely when destinations are on arterials. Again, we find that bicycle mode is not influenced by built environment characteristics at the destination.

3. Do built environment characteristics have a more pronounced association with mode shares at the establishment level than mode choices at the individual level?

Because the outcome variable of individual level analysis is the probability of choosing a particular mode and the outcome of establishment level analyses is the percent share of a 
particular mode, it is difficult to directly compare the coefficient magnitudes of the built environment factor variable and say expressly whether the effect is stronger at one analysis level than the other. The standardized coefficients, however, give a more clear understanding than unstandardized estimates because their interpretations are not affected by the variable type (e.g. a binary predictor's effect on the dependent variable is interpreted differently than that of a continuous variable).

In each set of models for walk and automobile travel mode, the magnitude of the coefficient for the built environment factor in the OLS model is larger relative to other variables in the OLS model than the relative size of the built environment factor coefficient in the logit choice model compared to other variables in that model. This suggests that the built environment surrounding the destination has a much more pronounced association with mode shares at the establishment than with mode choices of individuals. This is true for both standardized and unstandardized coefficients.

4. How do socio-demographic characteristics and attitudes impact personal travel choices?

At first glance of Table 42 , Table 43 , and Table 44 , it appears that very few aggregate socio-demographic characteristics have significant associations with mode shares. But in the mode choice models, either two or three socio-demographic variables have a significant impact. For walking choice, vehicle availability and presence of children are the relevant factors. For bicycling choice, income, gender, and age play a role. For vehicle choice, the significant socio-demographic variables are age, vehicle availability, and children in the household. 
In each of the three disaggregate mode choice models, at least one attitudinal measure is significantly related to the probability of choosing that mode in the expected direction. A positive attitude toward the particular mode in question is significant in all three. For example, a positive attitude towards walking significantly increases the odds of walking. In every case, a positive attitude towards the mode in consideration has at least a twofold increase of the probability of choosing to travel by that mode. For the walk model, the walking attitude variable had a fourfold effect on the odds of walking and was the largest predictor of all variables. These results suggest that improving public perceptions towards walking and bicycling are likely to increase non-motorized mode choices of individuals.

\section{What are the key differences in comparing results at the different analysis levels?}

The single key difference in results at the two analysis levels is that when individual socio-demographics and trip characteristics are aggregated to the site level, they seem to matter less than store type controls and the built environment. In the case of bicycling, socio-demographic and trip effects wash out completely with aggregation. For walking

and automobile modes, the effects lessen with aggregation. The store type controls and built environment effects gain importance when analysis moves from disaggregate to aggregate.

\subsection{Implications for Policy}

Historically, emphasis has been given to place-based policies that aim to create environments conducive to multimodal travel. These policies encourage more compact, dense, and mixed-use development connected by infrastructure appropriate for walking and bicycling. 
This is largely the domain of planners and engineers. More recently, there is some effort to incorporate social and psychological factors in analysis, driven by the realization that the built environment alone does not explain travel behavior as well as the built environment and attitudes (Ewing \& Cervero, 2010; Kitamura et al., 1997). Policies to promote behavioral change, expressly a shift away from automobile travel to the use of non-automobile modes, are now more prevalent (ITS Leeds, 2006) and have been influenced by programs from the health behavior modification field (for example, promoting physical activity or smoking cessation). These programs work to change attitudes and perceptions towards a behavior as the main way to achieve the desired behavioral change outcome.

Our analysis shows that different information is gleaned when data are analyzed at different levels. Although many researchers have claimed that disaggregate analysis is best, valid and useful results can still be obtained from aggregate analysis. The analysis we perform in this report suggests that in terms of transportation policy, a two-pronged approach where programs to change travel behavior through attitudes of individuals implemented along with programs to shape the built environment through infrastructure and/or site design would be the best strategy to increase active travel.

Pertaining consideration of modes, the differences in the bicycling models from the walking and vehicle models suggest on their own a move away from non-motorized travel to be considered as equivalent or assessed as one item in research and in practice. Instead, walking and bicycling should be examined separately. The physical movement 
through space is very different for walking and bicycling. An afternoon spent with a leisurely walk and bike ride will highlight the subtleties themselves.

\subsection{Limitations}

The comparison of disaggregate and aggregate analysis in this paper is inhibited by differing outcome variables. We interpret the models for factors related to mode-specific travel choices and modal splits, but we do not use the disaggregate travel choice data to predict mode splits. This may be part of the reason for the differences between the disaggregate and aggregate models.

The survey instrument was administered at a sample of convenience stores, restaurants, and bars. Participation was requested from many individual stores to be a part of the study. It was difficult to reach large chains due to organizational barriers, which resulted in the participation of mostly local stores. This may introduce bias towards smaller, locally owned establishments. Additionally, customers that patronize these smaller local establishments may in turn have a bias for opting for environmentally friendly modes of transportation. The results and findings are not generalizable to all retail establishments. Coupled with the sample itself, the nature of shopping varies greatly depending on store type.

Data were collected during summer months on nice weather days. The resulting mode shares may have been observed at the peak time of year for non-automobile travel. Behavior may be different in spring, fall, and winter months when weather is more variable and/or rainy. 
Data collection occurred between 5 p.m. and 7 p.m. This cross-section might not wholly represent customer traveler patterns. For example, using data from household travel surveys, we can see that the peak time of day for travel varies by mode and trip type. A time-of-day distribution of travel modes for shopping trips from 2011 Oregon Household Activity Survey data for Portland is shown below in Figure 5-1 (Oregon Department of Transportation, 2009). ${ }^{15}$ Each line represents the percentage of the mode share for shopping trips at different time intervals. The plot shows travel mode differences throughout the day - for example, 3:30 p.m. is the most common time for cyclists to go shopping, and the 5-7 p.m. data collection time seems to do an adequate job of capturing peak bicycle travel. A higher proportion of automobile shopping trips appear to occur between 5 and 7 p.m., suggesting that the percent mode share observed during this study may be biased to the time of day of data collection.

\footnotetext{
${ }^{15}$ Transit shopping trips are not shown due to a low sample size for this survey.
} 


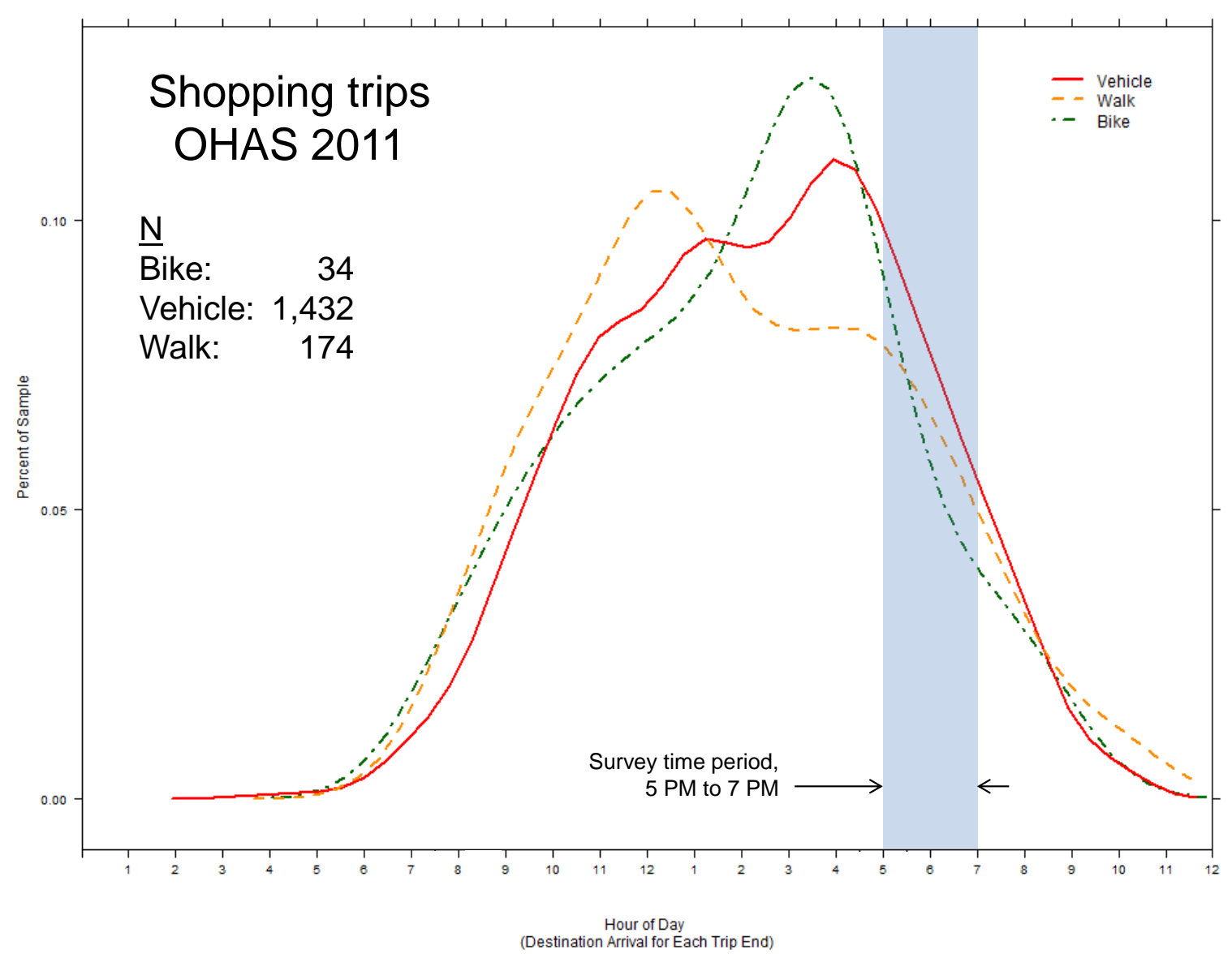

Figure 5-1. Time-of-Day Distribution of Travel Modes

The built environment was measured at the destination only. It would interesting to compare the effects of the built environment at the trip origin on travel behavior to see if the influence there is weaker or stronger than at the destination end of the trip.

Vehicle availability was included in the models as a binary variable representing whether at least one vehicle was owned or leased by a member of the household. This could be an issue because it does not indicate availability to the survey respondent at the time of the travel decision. Representing vehicle availability as the number of vehicles per household 
member or asking the question "was a vehicle available at the time of making this trip?" may have a different effect.

Trip distance was calculated along the road network shortest path. The coefficient for the trip distance variable in regression models may change slightly if network trip distance was calculated along the network specific to that mode. For example, it would be more appropriate to calculate the network shortest path trip distance for a person riding the bus along a bus route network instead of the entire street network.

Our data for travel mode perceptions are subject to findings in survey methods literature that shows that attitudinal variables may be biased and/or influenced by survey instruments (Richardson, Ampt, \& Meyburg, 1995). Attitude questionnaires are especially susceptible to social desirability bias, the idea that respondents tend to deceive their actual beliefs and behavior on surveys by answering questions according to prevailing social norms (Bonsall, 2009). In the context of the survey for this research, people in the Portland region might be more pro-environmentalism compared to other regions of the U.S. Upon learning that the survey was transportation-related and could have implications for regional policy, some respondents may have for example answered more positively for walk, bike, and transit attitude questions or more than under normal conditions. The question "how did you get here" was asked before the attitude questions, and the resulting attitude responses may have been different under a survey with a different question order. Another solution for avoiding this type of response bias is open ended questioning (Schuman \& Presser, 1979). But, because the survey instrument was 
administered on tablets, typing in responses would have proved difficult and this method was not used.

\subsection{Final Thoughts and Future work}

In conclusion, this research confirms previous travel behavior findings. We have shown that the use of active transportation increases when attitudes and the overall built environment support these modes.

This work could easily be performed on other datasets to form a more complete understanding of the influences on travel behavior according to different destination and trip types. A recent call to standardize ITE data collection for multimodal travel exists (Clifton, Currans, \& Muhs, 2013), and similar data collected at additional land uses through a similar travel survey instrument (see Appendix A) could allow for more destination types to be assessed. Including transit into the analysis would be another useful step. If a data collection procedure is implemented in the future similar to the one used for this project, it will be important to collect more observations of transit riders. Analyzing transit riders along with other modes may identify more relationships between travel modes. It would also be useful to collect a more temporally complete sample by extending data collection beyond the 5 p.m. to 7 p.m. time window, and by collecting data beyond the summer months.

Finally, the differing results gleamed from the individual and establishment models in this paper suggest that a modeling framework that could incorporate both levels at once would be a sound method of analysis. A hierarchical modeling construct would allow for travel outcomes to be estimated from characteristics of individuals in tandem with 
characteristics of the surrounding environment. The data used here has an inherent multilevel structure, and this could be taken into account with this modeling framework. Socio-demographic, trip, and attitudinal characteristics could be estimated at level one, the individual, and built environment characteristics could be tested at level two, the establishment. 


\section{Chapter 6. References}

Aditjandra, P. T., Cao, X. (Jason), \& Mulley, C. (2012). Understanding neighbourhood design impact on travel behaviour: An application of structural equations model to a British metropolitan data. Transportation Research Part A: Policy and Practice, 46(1), 22-32.

Afifi, A. A. A., Clark, V. A., \& May, S. (2004). Computer-Aided Multivariate Analysis. CRC Press.

Bochner, B. S., Hooper, K., Sperry, B., \& Dunphy, R. (2011). Enhancing Internal Trip Capture Estimation for Mixed-Use Developments. NCHRP Report, (684). Retrieved from http://trid.trb.org/view.aspx?id=1102368

Bohte, W., Maat, K., \& Van Wee, B. (2009). Measuring Attitudes in Research on Residential Self-Selection and Travel Behaviour: A Review of Theories and Empirical Research. Transport Reviews, 29(3), 325-357.

Bonsall, P. (2009). What is special about surveys designed to investigate the environmental sustainability of travel behaviour? Transport survey methods : keeping up with a changing world., 49-69.

Cao, X., Mokhtarian, P. L., \& Handy, S. L. (2009). Examining the Impacts of Residential Self-Selection on Travel Behaviour: A Focus on Empirical Findings. Transport Reviews, 29(3), 359-395.

Cervero, R., \& Gorham, R. (1995). Commuting in transit versus automobile neighborhoods. Journal of the American Planning Association, 61(2), 210.

Cervero, R., \& Kockelman, K. (1997). Travel demand and the 3Ds: Density, diversity, and design. Transportation Research Part D: Transport and Environment, 2(3), 199-219.

Chatman, D. G. (2005). How the built environment influences non-work travel: theoretical and empirical essays (PhD Dissertation). University of California Los Angeles, Los Angeles. Retrieved from http://164.67.121.27/files/Lewis_Center/Dissertations/chatman.pdf

Clifton, K. J., Currans, K. M., \& Muhs, C. D. (2012). Contextual Influences on Trip Generation (Project Report No. OTREC-RR-12-13). Portland, Oregon: Oregon Transportation Research and Education Consortium (OTREC). Retrieved from http://otrec.us/project/407/

Clifton, K. J., Currans, K. M., \& Muhs, C. D. (2013). Evolving the Institute for Transportation Engineers' Trip Generation Handbook: A Proposal for Collecting Multi-modal, Multi-context, Establishment-level Data. Presented at the 92nd Annual Meeting of the Transportation Research Board, Washington, D.C.

Clifton, K. J., Muhs, C. D., Morrissey, S., Morrissey, T., Currans, K. M., \& Ritter, C. (2013). Examining Consumer Behavior and Travel Choices (Project Report No. OTREC-RR-12-15). Portland, Oregon: Oregon Transportation Research and Education Consortium (OTREC). Retrieved from http://otrec.us/project/411

Clifton, K., \& Muhs, C. (2012). Capturing and Representing Multimodal Trips in Travel Surveys. Transportation Research Record: Journal of the Transportation Research Board, 2285, 74-83. 
Costello, A., \& Osborne, J. (2005). Best Practices in Exploratory Factor Analysis: Four Recommendations for Getting the Most From Your Analysis. Practical Assessment, Reserach \& Evaluation, 10(7).

Dill, J., \& Wardell, E. (2007). Factors Affecting Worksite Mode Choice: Findings from Portland, Oregon. Transportation Research Record: Journal of the Transportation Research Board, 1994, 51-57.

Ewing, R., \& Cervero, R. (2001). Travel and the Built Environment: A Synthesis. Transportation Research Record: Journal of the Transportation Research Board, $1780,87-114$.

Ewing, R., \& Cervero, R. (2010). Travel and the Built Environment. Journal of the American Planning Association, 76(3), 265-294.

Ewing, R., Pendall, R., \& Chen, D. (2003). Measuring Sprawl and Its Transportation Impacts. Transportation Research Record: Journal of the Transportation Research Board, 1831, 175-183.

Frank, L. D., Bradley, M., Kavage, S., Chapman, J., \& Lawton, T. K. (2008). Urban form, travel time, and cost relationships with tour complexity and mode choice. Transportation, 35(1), 37-54.

Frank, L. D., \& Engelke, P. O. (2001). The Built Environment and Human Activity Patterns: Exploring the Impacts of Urban Form on Public Health. Journal of Planning Literature, 16(2), 202-218.

Frank, L. D., Saelens, B. E., Powell, K. E., \& Chapman, J. E. (2007). Stepping towards causation: Do built environments or neighborhood and travel preferences explain physical activity, driving, and obesity? Social Science \& Medicine, 65(9), 18981914.

Handy, S. L. (1996). Understanding the Link Between Urban Form and Nonwork Travel Behavior. Journal of Planning Education and Research, 15(3), 183-198.

Handy, S. L., Boarnet, M. G., Ewing, R., \& Killingsworth, R. E. (2002). How the built environment affects physical activity: Views from urban planning. American Journal of Preventive Medicine, 23(2, Supplement 1), 64-73.

Handy, S. L., Cao, X., \& Mokhtarian, P. (2005). Correlation or causality between the built environment and travel behavior? Evidence from Northern California. Transportation Research Part D: Transport and Environment, 10(6), 427-444.

Handy, S. L., Shafizadeh, K., \& Schneider, R. J. (2013). California Smart-Growth Trip Generation Rates Study. Retrieved from http://ultrans.its.ucdavis.edu/projects/smart-growth-trip-generation

Handy, S. L., Xing, Y., \& Buehler, T. J. (2010). Factors associated with bicycle ownership and use: a study of six small U.S. cities. Transportation, 37(6), 967985.

Institute of Transportation Engineers. (2012). Trip Generation Manual (9th ed.). Washington, D.C.: ITE.

ITS Leeds. (2006). KonSULT Knowledge base on sustainable urban land use and transport. Institute for Transport Studies, University of Leeds. Retrieved from http://www.elseviersocialsciences.com/transport/konsult/

Joliffe, I. T. (1986). Principal Component Analysis (1st ed.). New York: Springer. 
King, G. (1997). A Solution to the Ecological Inference Problem: Reconstructing Individual Behavior from Aggregate Data. Princeton: Princeton University Press.

King, J. E. (2007). Standardized Coefficients in Logistic Regression. Presented at the Annual Meeting of the Southwest Educational Research Association, San Antonio, Texas. Retrieved from www.ccitonline.org/jking/homepage/standardized_paper.doc

Kitamura, R., Mokhtarian, P. L., \& Laidet, L. (1997). A micro-analysis of land use and travel in five neighborhoods in the San Francisco Bay Area. Transportation, 24(2), 125-158.

Messenger, T., \& Ewing, R. (1996). Transit-Oriented Development in the Sun Belt. Transportation Research Record: Journal of the Transportation Research Board, 1552(-1), 145-153.

Mokhtarian, P. L., \& Cao, X. (2008). Examining the impacts of residential self-selection on travel behavior: A focus on methodologies. Transportation Research Part B: Methodological, 42(3), 204-228.

Naess, P., \& Sandberg, S. L. (1996). Workplace Location, Modal Split and Energy Use for Commuting Trips. Urban Studies, 33(3), 557-580.

Oregon Department of Transportation. (2009, 2011). Oregon Travel \& Activity Survey (OHAS or OTAS).

Ortúzar, J. de D., \& Willumsen, L. G. (2001). Modelling transport (3rd ed.). New York: John Wiley and Sons.

Pampel, F. C. (2000). Logistic Regression: A Primer. London: SAGE. Retrieved from http://www.sagepub.com/books/Book10146?prodId=Book10146

Pas, E. (1985). State of the Art and Research Opportunities in Travel Demand: Another Perspective. Transportation Research Part A: Policy and Practice, 19A(5/6), 460-464.

Rajamani, J., Bhat, C., Handy, S., Knaap, G., \& Song, Y. (2003). Assessing Impact of Urban Form Measures on Nonwork Trip Mode Choice After Controlling for Demographic and Level-of-Service Effects. Transportation Research Record: Journal of the Transportation Research Board, 1831(-1), 158-165.

Richardson, A. J., Ampt, E. S., \& Meyburg, A. H. (1995). Survey methods for transport planning. Melbourne, Vic., Australia: Eucalyptus Press.

Robinson, W. S. (2009). Ecological Correlations and the Behavior of Individuals. International Journal of Epidemiology, 38(2), 337-341.

Saelens, B. E., \& Handy, S. L. (2008). Built Environment Correlates of Walking: A Review. Medicine and science in sports and exercise, 40(7), 550-566.

Saelens, B. E., Sallis, J. F., \& Frank, L. D. (2003). Environmental correlates of walking and cycling: Findings from the transportation, urban design, and planning literatures. Annals of Behavioral Medicine, 25(2), 80-91.

Santos, A., McGucklin, N., Nakamoto, H. Y., Gray, D., \& Liss, S. (2011). Summary of Travel Trends: 2009 National Household Travel Survey (No. FHWA-PL-11-022). Federal Highway Administration. Retrieved from http://nhts.ornl.gov/2009/pub/stt.pdf 
Schneider, R. J. (2011). Understanding Sustainable Transportation Choices: Shifting Routine Automobile Travel to Walking and Bicycling. Retrieved from http://www.escholarship.org/uc/item/06v2g6dh

Schuman, H., \& Presser, S. (1979). The Open and Closed Question. American Sociological Review, 44(5).

Snijders, T. A. B., \& Bosker, R. J. (2011). Multilevel Analysis: An Introduction to Basic and Advanced Multilevel Modeling (2nd ed.). SAGE.

Steiner, R. L. (1997, October 1). Traditional Neighborhood Shopping Districts: Patterns of Use and Modes of Access (PhD Dissertation). University of California Berkeley, Berkeley. Retrieved from http://www.escholarship.org/uc/item/7258f369

Taylor, M. A. P., \& Ampt, E. S. (2003). Travelling smarter down under: policies for voluntary travel behaviour change in Australia. Transport Policy, 10(3), 165-177.

Van Acker, V., Mokhtarian, P., \& Witlox, F. (2011). Going soft: on how subjective variables explain modal choices for leisure travel. European Journal of Transport and Infrastructure Research, 11(2), 115-146.

Zhang, M. (2004). The Role of Land Use in Travel Mode Choice: Evidence from Boston and Hong Kong. Journal of the American Planning Association, 70(3), 344-360. 


\section{Appendix A. Long Survey Instrument}

Note: The survey in the study was administered electronically on electronic computer tablets. The instrument here is a paper version that was to be used if the electronic survey malfunctioned.

\begin{tabular}{|c|c|c|}
\hline Question & Text To Read to Respondent & Answers \\
\hline Q1. Age & What best describes your AGE? & $\begin{array}{l}\text { [ ] under 18, [ ] 18-24, [ ] 25-34, [ ] 35-44, } \\
\text { [ ] 45-54, [ ] 55-64, [ ] 65-74, [ ] } 75 \text { and over }\end{array}$ \\
\hline \multirow[t]{5}{*}{ Q2. HH } & $\begin{array}{l}\text { Please provide the following } \\
\text { information for your household: } \\
\text { Number of Adults }\end{array}$ & {$[$ ] $0,[$ ] 1, [ ] 2, [ ] 3, [ ] 4, [ ] 5 or more } \\
\hline & Number of Children & {$[$ ] $0,[] 1,[] 2,[] 3,[] 4,[] 5$ or more } \\
\hline & Number of Automobiles & {$[\mathrm{]} 0,[\mathrm{]} 1,[\mathrm{]}] 2,[\mathrm{]} 3,[\mathrm{]}, 4,[\mathrm{]} 5$ or more } \\
\hline & Number of people with BICYCLES & {$[$ ] $0,[] 1,[] 2,[] 3,[] 4,[$ ] 5 or more } \\
\hline & Number of Transit Passes & {$[$ ] $0,[$ ] 1, [ ] 2, [ ] 3, [ ] 4, [ ] 5 or more } \\
\hline $\begin{array}{l}\text { Q3. } \\
\text { Decision }\end{array}$ & $\begin{array}{l}\text { When did you decide that you would } \\
\text { visit [LOCATION]? }\end{array}$ & $\begin{array}{l}\text { [ ] passing by, [ ] after leaving home, [ ] today } \\
\text { before leaving home, [ ] yesterday, [ ] before } \\
\text { yesterday, [ ] do not know }\end{array}$ \\
\hline Q4. Origin & $\begin{array}{l}\text { We would like to ask you some } \\
\text { questions about your travel here } \\
\text { today, Can you tell me the nearest } \\
\text { intersection or address from where } \\
\text { you came from? }\end{array}$ & Identify location with Google Map \\
\hline $\begin{array}{l}\text { Q5. } \\
\text { Beginning } \\
\text { of Day }\end{array}$ & $\begin{array}{l}\text { Is this the place where you began } \\
\text { your day? }\end{array}$ & [ ] yes, [ ] no \\
\hline $\begin{array}{l}\text { Q6. Origin } \\
\text { Type }\end{array}$ & $\begin{array}{l}\text { The best description of this location } \\
\text { is one of the following: }\end{array}$ & $\begin{array}{l}\text { [ ] Home, [ ] Work, [ ] School, } \\
\text { [ ]Restaurant, } \\
\text { [ ] Coffee shop, [ ] Service errand, } \\
\text { [ ] Other: }\end{array}$ \\
\hline
\end{tabular}




\begin{tabular}{|c|c|c|}
\hline Question & Text To Read to Respondent & Answers \\
\hline \multirow{8}{*}{$\begin{array}{l}\text { Q7. Origin } \\
\text { Mode }\end{array}$} & \multicolumn{2}{|l|}{ How did you travel to [establishment]? } \\
\hline & \multicolumn{2}{|c|}{$\begin{array}{l}\text { Explain that we want travel modes in the order used. } \\
\text { respondent for walk trips if }>1 \text { block. }\end{array}$} \\
\hline & \multicolumn{2}{|c|}{$\begin{array}{l}\text { Segment 1: [ ] Walk, [ ] Bicycle, [ ] MAX/WES, [ ] Bus, [ ] Streetcar, [ ] Vehicle-driver, } \\
\text { [ ]Vehicle-passenger, [ ] Other: }\end{array}$} \\
\hline & \multicolumn{2}{|c|}{$\begin{array}{l}\text { Segment 2: [ ] Walk, [ ] Bicycle, [ ] MAX/WES, [ ] Bus, [ ] Streetcar, [ ] Vehicle-driver, } \\
\text { [ ]Vehicle-passenger, [ ] Other: }\end{array}$} \\
\hline & \multicolumn{2}{|c|}{$\begin{array}{l}\text { Segment 3: [ ] Walk, [ ] Bicycle, [ ] MAX/WES, [ ] Bus, [ ] Streetcar, [ ] Vehicle-driver, } \\
\text { [ ]Vehicle-passenger, [ ] Other: }\end{array}$} \\
\hline & \multicolumn{2}{|c|}{$\begin{array}{l}\text { Segment 4: [ ] Walk, [ ] Bicycle, [ ] MAX/WES, [ ] Bus, [ ] Streetcar, [ ] Vehicle-driver, } \\
\text { [ ]Vehicle-passenger, [ ] Other: }\end{array}$} \\
\hline & \multirow{2}{*}{\multicolumn{2}{|c|}{$\begin{array}{l}\text { Segment 5: [ ] Walk, [ ] Bicycle, [ ] MAX/WES, [ ] Bus, [ ] Streetcar, [ ] Vehicle-driver, } \\
\text { [ ]Vehicle-passenger, [ ] Other:- } \\
\text { Segment 6: [ ] Walk, [ ] Bicycle, [ ] MAX/WES, [ ] Bus, [ ] Streetcar, [ ] Vehicle-driver, } \\
\text { [ ]Vehicle-passenger, [ ] Other: }\end{array}$}} \\
\hline & & \\
\hline $\begin{array}{l}\text { Q8. Veh } \\
\text { Occ }\end{array}$ & $\begin{array}{l}\text { IF VEHICLE CHOSEN: For trip } \\
\text { segment [\#], how many people were } \\
\text { in the vehicle? }\end{array}$ & {$[$ ] $1,[$ ] 2, [ ] 3, [ ] 4, [ ] 5 or more } \\
\hline $\begin{array}{l}\text { Q9. Parking } \\
\text { cost }\end{array}$ & $\begin{array}{l}\text { IF VEHICLE CHOSEN: How } \\
\text { much did you pay for PARKING in } \\
\text { traveling to [LOCATION]? (Enter } \\
\text { zero if you have a parking pass) }\end{array}$ & $\$$ \\
\hline $\begin{array}{l}\text { Q10. } \\
\text { Transit Cost }\end{array}$ & $\begin{array}{l}\text { IF TRANSIT CHOSEN: How did } \\
\text { you pay for your public } \\
\text { transportation in travelling to } \\
\text { [LOCATION] today? }\end{array}$ & $\begin{array}{l}\text { [ ] cash only, [ ] ticket at kiosk, [ ] transit pass, [ ] } \\
\text { free zone }\end{array}$ \\
\hline \multirow[t]{6}{*}{$\begin{array}{l}\text { Q11. Mode } \\
\text { Attitudes }\end{array}$} & \multicolumn{2}{|c|}{$\begin{array}{l}\text { Now, we will ask you about your attitudes towards different transportation options in } \\
\text { traveling to [LOCATION]. Please evaluate the following on a scale from } 1 \text { (strongly } \\
\text { disagree) to } 5 \text { (strongly agree), even if you do not use these modes: }\end{array}$} \\
\hline & $\begin{array}{l}\text { Car parking here is easy and } \\
\text { convenient }\end{array}$ & {$[\mathrm{]} 1,[\mathrm{]} 2,[\mathrm{]} 3,[\mathrm{]} 4,[\mathrm{]} 5$} \\
\hline & $\begin{array}{l}\text { Bike parking here is easy and } \\
\text { convenient }\end{array}$ & {$[\mathrm{]} 1,[\mathrm{]} 2,[\mathrm{]} 3,[\mathrm{]} 4,[\mathrm{]} 5$} \\
\hline & Biking here is safe and comfortable & [ ] 1, [ ]2,[ ]3,[ ] 4, [ ] 5 \\
\hline & $\begin{array}{l}\text { Walking here is safe and } \\
\text { comfortable }\end{array}$ & {$[\mathrm{]} 1,[\mathrm{]} 2,[\mathrm{]} 3,[\mathrm{]} 4,[\mathrm{]} 5$} \\
\hline & Taking transit here is convenient & {$[\mathrm{]} 1,[\mathrm{]}] 2,[\mathrm{]} 3,[\mathrm{]}] 4,[\mathrm{]} 5$} \\
\hline
\end{tabular}




\begin{tabular}{|c|c|c|}
\hline Question & Text To Read to Respondent & Answers \\
\hline $\begin{array}{l}\text { Q12. } \\
\text { Shopping } \\
\text { frequency }\end{array}$ & $\begin{array}{l}\text { In order to understand more about } \\
\text { why you came here, we will ask a } \\
\text { few questions about your consumer } \\
\text { habits. Can you tell me how } \\
\text { frequently you come here? }\end{array}$ & $\begin{array}{l}\text { [ ] rarely, [ ] once a month, [ ] a few times per } \\
\text { month, } \\
\text { [ ] once a week, [ ] a few times a week, [ ] daily }\end{array}$ \\
\hline $\begin{array}{l}\text { Q13. Time } \\
\text { spent }\end{array}$ & $\begin{array}{l}\text { Could you tell me the approximate } \\
\text { amount of TIME you spent here at } \\
\text { [LOCATION] }\end{array}$ & Minutes \\
\hline $\begin{array}{l}\text { Q14. } \\
\text { Money } \\
\text { spent }\end{array}$ & $\begin{array}{l}\text { Could you tell me the approximate } \\
\text { amount of money you spent here at } \\
\text { [LOCATION]? }\end{array}$ & $\$$ \\
\hline $\begin{array}{l}\text { Q15. Group } \\
\text { size }\end{array}$ & $\begin{array}{l}\text { How many people in your group did } \\
\text { this purchase pay for? }\end{array}$ & {$[$ ] $1,[$ ] 2, [ ] 3, [ ] 4, [ ] 5 or more } \\
\hline $\begin{array}{l}\text { Q16. } \\
\text { Destination } \\
\text { location }\end{array}$ & $\begin{array}{l}\text { We are going to ask you a series of } \\
\text { questions about where you will be } \\
\text { going after [Location]. Can you tell } \\
\text { me the nearest intersection or } \\
\text { address you will be going NEXT? }\end{array}$ & Identify location with Google Map \\
\hline $\begin{array}{l}\text { Q17. } \\
\text { Destination } \\
\text { type }\end{array}$ & $\begin{array}{l}\text { The best description of this location } \\
\text { is one of the following: }\end{array}$ & $\begin{array}{l}\text { [ ] Home, [ ] Work, [ ] School, [ ]Restaurant, } \\
\text { [ ] Coffee shop, [ ] Service errand, } \\
\text { [] Other: }\end{array}$ \\
\hline \multirow[t]{7}{*}{$\begin{array}{l}\text { Q18. } \\
\text { Destination } \\
\text { mode }\end{array}$} & \multicolumn{2}{|c|}{$\begin{array}{l}\text { Explain that we want travel modes in the order used. } \\
\text { respondent for walk trips if }>1 \text { block. }\end{array}$} \\
\hline & \multicolumn{2}{|c|}{$\begin{array}{l}\text { Segment 1: [ ] Walk, [ ] Bicycle, [ ] MAX/WES, [ ] Bus, [ ] Streetcar, [ ] Vehicle-driver, } \\
\text { [ ]Vehicle-passenger, [ ] Other: }\end{array}$} \\
\hline & \multicolumn{2}{|c|}{$\begin{array}{l}\text { Segment 2: [ ] Walk, [ ] Bicycle, [ ] MAX/WES, [ ] Bus, [ ] Streetcar, [ ] Vehicle-driver, } \\
\text { [ ]Vehicle-passenger, [ ] Other: }\end{array}$} \\
\hline & \multicolumn{2}{|c|}{$\begin{array}{l}\text { Segment 3: [ ] Walk, [ ] Bicycle, [ ] MAX/WES, [ ] Bus, [ ] Streetcar, [ ] Vehicle-driver, } \\
\text { [ ]Vehicle-passenger, [ ] Other: }\end{array}$} \\
\hline & \multicolumn{2}{|c|}{$\begin{array}{l}\text { Segment 4: [ ] Walk, [ ] Bicycle, [ ] MAX/WES, [ ] Bus, [ ] Streetcar, [ ] Vehicle-driver, } \\
\text { [ ]Vehicle-passenger, [ ] Other: }\end{array}$} \\
\hline & \multicolumn{2}{|c|}{$\begin{array}{l}\text { Segment 5: [ ] Walk, [ ] Bicycle, [ ] MAX/WES, [ ] Bus, [ ] Streetcar, [ ] Vehicle-driver, } \\
\text { [ ]Vehicle-passenger, [ ] Other: }\end{array}$} \\
\hline & \multicolumn{2}{|c|}{$\begin{array}{l}\text { Segment 6: [ ] Walk, [ ] Bicycle, [ ] MAX/WES, [ ] Bus, [ ] Streetcar, [ ] Vehicle-driver, } \\
\text { [ ]Vehicle-passenger, [ ] Other: }\end{array}$} \\
\hline $\begin{array}{l}\text { Q19. Home } \\
\text { location }\end{array}$ & $\begin{array}{l}\text { IF HOME NOT ALREADY } \\
\text { GIVEN IN } \\
\text { ORIGIN/DESTINATION } \\
\text { QUESTIONS: Can you tell me the } \\
\text { nearest intersection or address for } \\
\text { your HOME? }\end{array}$ & Identify location with Google Map \\
\hline
\end{tabular}




\begin{tabular}{|c|c|c|}
\hline Question & Text To Read to Respondent & Answers \\
\hline $\begin{array}{l}\text { Q20. Work } \\
\text { location }\end{array}$ & $\begin{array}{l}\text { IF WORK NOT ALREADY } \\
\text { GIVEN IN } \\
\text { ORIGIN/DESTINATION } \\
\text { QUESTIONS Can you tell me the } \\
\text { nearest intersection or address for } \\
\text { your WORK? }\end{array}$ & Identify location with Google Map \\
\hline $\begin{array}{l}\text { Q21. } \\
\text { Limitations }\end{array}$ & $\begin{array}{l}\text { Do you have any medical limitations } \\
\text { that prevent you from walking, } \\
\text { bicycling or driving? }\end{array}$ & [ ] yes, [ ] no \\
\hline $\begin{array}{l}\text { Q22. HH } \\
\text { Income }\end{array}$ & $\begin{array}{l}\text { What best describes your total } \\
\text { annual HOUSEHOLD INCOME? }\end{array}$ & $\begin{array}{l}\text { [ ] less than } \$ 25,000 \text {, [ ] } \$ 25 \mathrm{~K}-\$ 49,999, \text { [ ] } \$ 50 \mathrm{~K}- \\
\$ 99,999, \\
\text { [ ] } \$ 100 \mathrm{~K}-\$ 149,999,[\text { ] } \$ 150 \mathrm{~K}-\$ 199,999,[\text { ] } \\
\$ 200 \mathrm{~K} \text { or more }\end{array}$ \\
\hline $\begin{array}{l}\text { Q23. } \\
\text { Gender }\end{array}$ & $\begin{array}{l}\text { What gender do you most identify } \\
\text { with? }\end{array}$ & [ ] male, [ ] female \\
\hline $\begin{array}{l}\text { Q24. } \\
\text { Follow up }\end{array}$ & $\begin{array}{l}\text { Finally, would you like to } \\
\text { participate in follow-up research } \\
\text { about travel \& consumer choices? }\end{array}$ & $\begin{array}{l}\text { Name: } \\
\text { Phone/email: }\end{array}$ \\
\hline END & \multicolumn{2}{|c|}{ We appreciate your time in completing this survey. Thank you, and have a great day! } \\
\hline
\end{tabular}




\section{Appendix B. Short Survey Instrument}

\section{Contextual Influences on Trip Generation Survey II}

Location:

Date:

Thank you for taking this 30 second survey about your travel choices and consumer behavior. The information you provide will inform Portland State University research about transportation, environment and behavior. Your participation in this study is voluntary, your information will be kept confidential and you can opt out at any time.

Questions:

1. How did you get here? (multiple modes allowed)

(Walk; Bicycle; MAX/WES; Bus; Streetcar; Vehicle driver; Vehicle passenger; Other--write in)

2. Can you tell me the nearest intersection or address to/of your home?

3. Can you tell me how frequently you come to this plaid pantry?

(Rarely; Once / month; A few times / month; Once / week; A few times / week; Daily)

4. Could you tell me the approximate amount of money you spent here during this visit?

Survey administrator circles $\mathrm{M}$ for male respondents and $\mathrm{F}$ for Female respondents. 


\section{Appendix C. Site Data Collection Sheet}

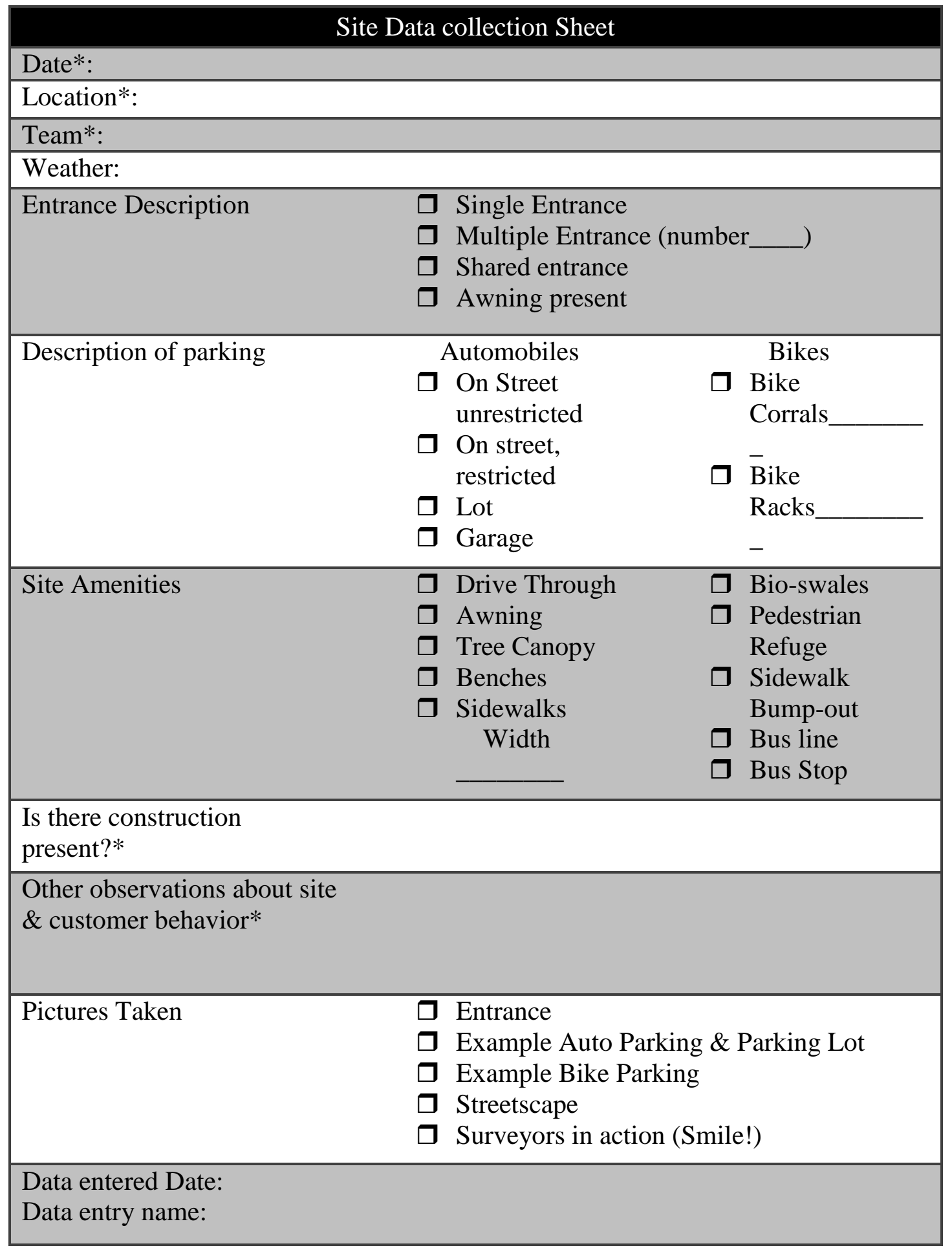




\section{Appendix D. Data Preparation}

Variables were manipulated after data were gathered from intercept surveys. This appendix describes the recoding and classification of long survey data for input into the regression models Chapter 4.

Travel modes were recoded as binary variables for logistic regression analysis. The mode of travel from the origin to establishment was used. These variables were used as dependent variables in regression models.

Physical limitations were coded as a dummy variable. Household income was collected in $\$ 25,000$ and $\$ 50,000$ categories. Because the categories were not evenly spaced-i.e. one category was $\$ 25,000$ to $\$ 49,000$ and another was $\$ 50,000$ to $\$ 99,999$ - the midpoints of the categories were used and treated as continuous values in choice models. Gender was dummy coded as $0=$ female and $1=$ male.

The age category consists of two bins: individuals under 35 and individuals 35 or older. The survey instrument collected age in the following bins: under 18, 18-24, 25-34, 35-64, 65-74, and 75+. Due to sample sizes across bins when segmented by modes, the age categories used in choice models are under 35 years of age and 35 or older. Although the elderly may exhibit travel behavior different than other population groups, the sample had 18 observations of age above 64, so theses respondents are included in the 35 or older group.

Vehicle availability was coded as a dummy variable representing whether at least one vehicle was owned or leased by a member of the household. The presence of children in the household variable was also dummy coded. 
Home-based and work-based trips were dummy coded as well. A home-based trip means that the place the traveler originated from before visiting the survey establishment or the place to which the traveler went after the survey establishment was home. A work-based trip means that work was the previous place before the survey establishment or the next place visited after the survey establishment.

Trip distance was calculated as miles along the roadway network shortest path. The distance used was calculated from the trip origin to the survey establishment.

Attitudes were dummy coded into whether the traveler agreed or disagreed with the attitude responses. Table D-1 illustrates the method: if the respondent reported they disagreed or strongly disagreed with the statement, they were coded as a negative attitude for that attitude category. If they reported that they agreed or strongly agreed with the statement, they were coded as a positive attitude for that category.

\section{Table D-1. Attitude Question Coding}

\begin{tabular}{|c|c|c|c|c|c|}
\hline \multicolumn{6}{|c|}{ Example Survey Statement: "Walking here is safe \& comfortable" } \\
\hline Survey response & 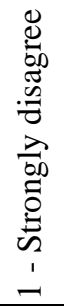 & 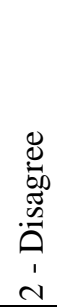 & 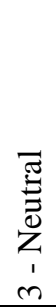 & 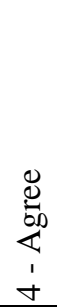 & 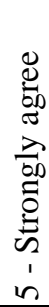 \\
\hline Coding for agreement / positive walking attitude & 0 & 0 & 0 & 1 & 1 \\
\hline Coding for disagreement / negative walking attitude & 1 & 1 & 0 & 0 & 0 \\
\hline
\end{tabular}




\section{Appendix E. Standardized Estimates for Binary Logistic Regression Models}

Standardizing regression estimates is useful for comparing effects of independent variables that are measured differently than one another (e.g. binary variables and Likert scale variables) on the dependent variable (J. E. King, 2007). To do so, variables are placed on a common scale where each has the same mean and standard deviation before regression analysis. The resulting absolute values of the standardized regression weights are then comparable.

This process, which is part of the usual output of linear regression models in statistical packages including SPSS, is not typical for logistic regression output. Unlike linear regression where the outcome variable is continuous, there is no single method of calculating standardized estimates for logistic regression. This is because the dependent variable in the regression equation is the log odds of a binary outcome, which is a mathematical transformation with limits of $-\infty$ to $+\infty$ and an arbitrarily defined variance (Pampel, 2000). Also, some researchers prefer "partial-" or "semi-standardization" where standard deviations of only the independent variables are accounted for, where others call for "full standardization," where the standard deviations of the dependent and independent variable are accounted for (J. E. King, 2007; Pampel, 2000).

The standardized regression estimates reported in the binary logistic models in this thesis use full standardization and the method described in (Pampel, 2000, p. 35). The steps are: 
1. Save the predicted probabilities from logistic regression

2. Correlate the predicted probabilities with the binary dependent variable to obtain $R$ and $R^{2}$ of the model

3. Transform predicted probabilities ( $p$; from step 1$)$ into predicted logits, where

$$
\operatorname{logit}(p)=\ln \left(\frac{p}{1-p}\right)
$$

4. Calculate the variance of the predicted logits

5. Compute standard deviation of predicted logits $\left(S D_{\hat{Y}}\right)$ as the square root of the variance of the predicted logits divided by $R^{2}$ :

$$
S D_{\hat{Y}}=\sqrt{\frac{\operatorname{Var}\left(\operatorname{logit}_{\hat{Y}}\right)}{R^{2}}}=\sqrt{\frac{\operatorname{Var}\left(\text { logit }_{\hat{Y}}\right)}{\operatorname{Var}\left(\text { explained }_{\text {model }}\right)}}
$$

6. Compute sample standard deviations of independent variables $\left(S D_{X}\right)$ and calculate standardized coefficient estimates $\left(\beta_{\text {logistic }}\right)$ as:

$$
\beta_{\text {logistic }}=b_{X}\left(\frac{S D_{X}}{S D_{\widehat{Y}}}\right),
$$

where $b_{X}$ is the unstandardized logistic regression coefficient estimate. 